\title{
Assessment of shelf sea tides and tidal mixing fronts in a global ocean model
}

\author{
Patrick G. Timko, ${ }^{\mathrm{a}, \mathrm{b}, *}$, Brian K. Arbic ${ }^{\mathrm{b}, \mathrm{c}}$, Patrick Hyder ${ }^{\mathrm{d}}$, James G. Richman ${ }^{\mathrm{e}}$, Luis Zamudio ${ }^{\mathrm{e}}$, \\ Enda O'Dea ${ }^{\mathrm{d}}$, Alan J. Wallcraft ${ }^{\mathrm{e}}$, Jay F. Shriver ${ }^{\mathrm{f}}$ \\ ${ }^{a}$ Welsh Local Centre, Royal Meteorological Society, UK \\ ${ }^{\mathrm{b}}$ Department of Earth and Environmental Sciences, University of Michigan, Ann Arbor, MI, USA \\ ${ }^{\mathrm{c}}$ Currently on sabbatical at Institut des Géosciences de L'Environnement (IGE), Grenoble, France, and Laboratoire des Etudes en Géophysique et Océanographie Spatiale \\ (LEGOS), Toulouse, France \\ ${ }^{\mathrm{d}}$ UK Met Office, Exeter, UK \\ ${ }^{\mathrm{e}}$ Center for Ocean - Atmospheric Prediction Studies, Florida State University, Florida, USA \\ ${ }^{\mathrm{f}}$ Naval Research Laboratory, Stennis Space Center, MS, USA
}

\section{A B S T R A C T}

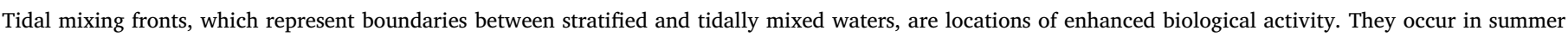

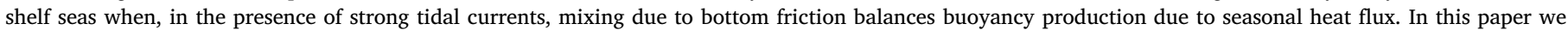

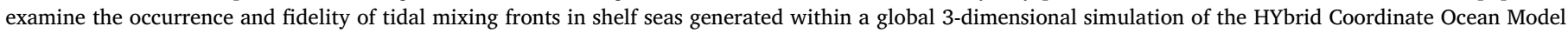

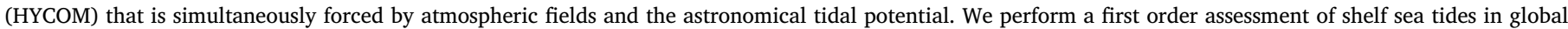

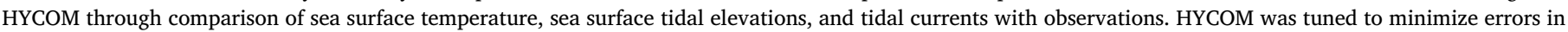

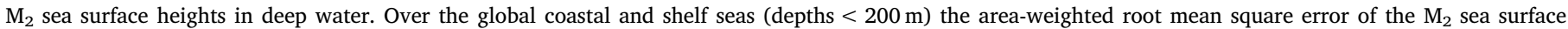

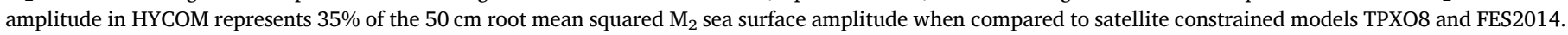

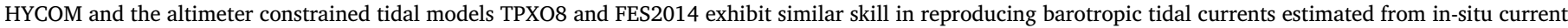

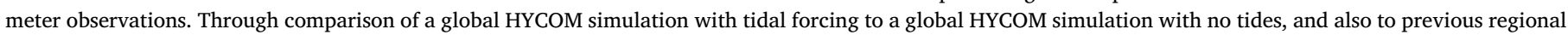

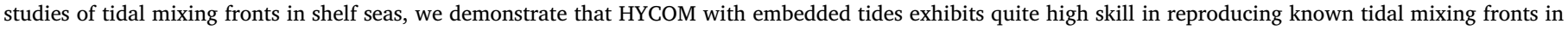

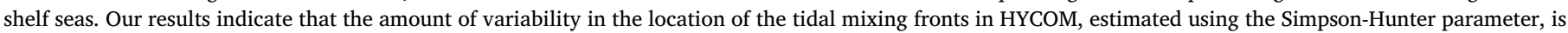

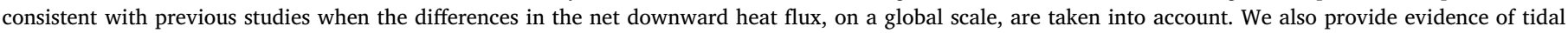
mixing fronts on the North West Australian Shelf for which we have been unable to find references in the existing scientific literature.

\section{Introduction}

The coastal and shelf seas represent less than $10 \%$ of the world's oceans yet have an important role in primary production and the global carbon cycle. This role, however, is poorly understood (Bauer et al., 2013). On a regional scale there are many different factors, such as riverine input, sediment transport, nutrient availability, coastal geometry and bathymetry that may affect the local biogeochemical cycle. Local mixing rates within the water column impact pelagic ecosystems and may enhance or inhibit growth rates. Within coastal and shelf seas the boundary between mixed and stratified waters is represented by persistent seasonal mixing fronts that occur when mixing due to tidal and wind forcing balances buoyancy production due to surface heat flux. Such fronts are regions of high biological activity and hence can be expected to play a role in the biogeochemical cycle. Belkin et al. (2009) provides a comprehensive review of the location of known oceanic fronts based upon satellite sea surface temperature observations in selected large marine ecosystems.

Coastal and shelf seas are also regions of large tidal energy dissipation. Egbert and Ray (2003) estimated that about 2/3 of the total $\mathrm{M}_{2}$ tidal dissipation occurs in shallow seas. Tidal mixing also influences coastal sea surface temperatures, which impact regional climates. Hence the accuracy of tides in the coastal regions of global tide models needs to be assessed.

Most modelling studies of coastal and shelf seas are conducted using limited area regional models. Very few modelling studies (e.g. Holt et al., 2009) have been conducted to model the global coastal ocean. Recent developments of the global version of the HYbrid Coordinate Ocean Model (HYCOM: Chassignet et al., 2009) include the implementation of a forward tide algorithm based upon astronomical arguments (Arbic et al., 2010, 2012, 2018). At current horizontal grid resolutions of $1 / 12.5^{\circ}$ and $1 / 25^{\circ}$ global HYCOM is able to resolve the continental margins and hence is able to resolve features such as mixing fronts in the coastal and shelf seas. Previous studies of the skill of global

\footnotetext{
* Corresponding author now at: MetEnvironment and Climate Change Canada.

E-mail address: ptimko@umich.edu (P.G. Timko).
} 
HYCOM with embedded tides have examined the sea surface elevation signature of surface and internal tides (Ansong et al., 2015; Ngodock et al., 2016; Savage et al., 2017; Shriver et al., 2012, 2014; Stammer et al., 2014), tidal currents (Timko et al., 2012, 2013), and barotropic and baroclinic tidal energetics (Ansong et al., 2017; Buijsman et al., 2015, 2016). Most of the aforementioned HYCOM studies have focussed on model performance in deep waters, where water column depth exceeds $1000 \mathrm{~m}$ or $1500 \mathrm{~m}$. Stammer et al. (2014) briefly discussed HYCOM tidal elevation errors over the shelf seas. Savage et al. (2017) compared tidal elevation variances in HYCOM vs. tide gauges. In this paper we focus on a comparison of HYCOM tidal elevations and currents vs. observations on the shelf, and we investigate the occurrence and location of tidal mixing fronts in a global HYCOM simulation.

Accurate simulation of tides in coastal and shelf regions requires accurate tidal forcing at the shelf edge and good representation of shallow water processes such as bottom friction and features such as coastline geometry and bathymetry. Such factors influence the propagation and superposition of tidal constituents on the shelf as well as mixing in the continental margins. Within these shallow regions the dissipation of tidal energy is primarily due to bottom friction. As discussed in Arbic et al. (2010) and Buijsman et al. (2016) HYCOM uses an internal wave drag scheme applied in the bottom $500 \mathrm{~m}$ of the water column to improve the accuracy of sea surface $\mathrm{M}_{2}$ tidal heights over deep water ( $>1500 \mathrm{~m}$ ). The wave drag scheme is not applied when the water column is $<500 \mathrm{~m}$ depth. In this paper we examine HYCOM skill in replicating observed tides in regional and shelf seas where water column depth is, typically, $200 \mathrm{~m}$ or less.

A mixing front represents the location where the water column changes from being stratified to well-mixed. A simple measure of stratification is the difference, $\Delta T=S S T-S B T$, between the sea surface temperature (SST) and seabed temperature (SBT). Wind driven mixing can be expected to maintain well-mixed waters $\left(\Delta T \leq 0.5^{\circ} \mathrm{C}\right)$ when the water column depth is $<30 \mathrm{~m}$ (Bowers and Simpson, 1987). Strong currents produce bottom friction that results in additional mixing (Simpson, 1981). Tidal mixing fronts form in water column depths between 50 and $100 \mathrm{~m}$ when mixing due to dissipation of tidal currents balances buoyancy production due to incoming solar radiation (Simpson and Hunter, 1974). The $\Delta T=0.5^{\circ} \mathrm{C}$ degree contour may be somewhat ambiguous for determination of the mixing front locations. Another measure of the stratification, based upon the potential energy anomaly,

$\varphi=\frac{1}{h} \int_{-h}^{0}(\rho-\bar{\rho}) g z d z \bar{\rho}=\frac{1}{h} \int_{-h}^{0} \rho d z$

may be used to define the location of a mixing front whereby $|\nabla \varphi|$ exceeds a threshold value as $\varphi \rightarrow 0$ (J. Simpson, personal communication). Within this paper we identify mixing front locations using the $\Delta T=0.5^{\circ} \mathrm{C}$ degree contour and also define fronts as those regions for which $|\nabla \varphi|>2.5 \cdot 10^{-4}$ and $\varphi<10 \mathrm{~J} \mathrm{~m}^{-3}$. In general, we find that the $\Delta T=0.5^{\circ} \mathrm{C}$ degree contour provides a reasonable proxy for the location of mixing fronts identified using the potential energy anomaly. Identification of mixing front locations using the $\Delta T=0.5^{\circ} \mathrm{C}$ contour is useful as the potential energy anomaly and its gradient are more computationally expensive to estimate.

The balance between tidal dissipation and buoyancy production may be defined by the ratio, R, (Pingree and Griffiths, 1978):

$R=\frac{g \alpha Q h / 2 C_{p}}{\rho C_{d} u^{3}}$,

where $g$ is the acceleration due to gravity, $\alpha$ is the volume coefficient of expansion, $Q$ is the net downward surface heat flux, $h$ is the depth of the water column, $C_{p}$ is the specific heat at constant pressure, $\rho$ is the density of seawater, $C_{d}$ is the bottom drag coefficient, and $u$ is the depth averaged velocity. On a regional scale $g, \alpha, C_{p}, \rho, C_{d}$ may be assumed constant so that:
$R \propto \frac{Q h}{u^{3}}$.

$R$ is non-dimensional hence we can rewrite Eq. (2a) as:

$\log _{10}(R)=\log _{10}\left(\frac{g \alpha Q h / 2 C_{p}}{\rho C_{d} u^{3}}\right)=\log _{10}\left(\frac{g \alpha}{2 C_{p} \rho C_{d}}\right)+\log _{10}\left(\frac{Q h}{u^{3}}\right)$.

Assuming that $g, \alpha, C p, \rho, C_{d}$ are constant (locally) then:

$\log _{10}(R)=C+\log _{10}\left(\frac{Q h}{u^{3}}\right)=C+S_{Q}$,

where: $C=\log _{10}\left(g \alpha / 2 C_{p} \rho C_{d}\right)$ and:

$S_{Q}=\log _{10}\left(\frac{Q h}{u^{3}}\right)$.

Assuming: $g \sim 9.81 \mathrm{~ms}^{-2}, \alpha \sim 2.1 \cdot 10^{-4}{ }^{\circ} \mathrm{C}^{-1}$ (when $S=34$ PSU, $T=15^{\circ} \mathrm{C}$ at zero pressure), $C p \sim 4000 \mathrm{~J} \mathrm{~kg}^{-1}{ }^{\circ} \mathrm{C}^{-1}, \rho \sim 1025 \mathrm{~kg} \mathrm{~m}^{-3}$, $C_{d} \sim 0.0025$ we have, $C \sim-7.0$. So that, to leading order, $\mathrm{S}_{\mathrm{Q}} \sim$ $\log _{10}(R)-C=\log _{10}(R)+7.0$ represents the logarithm of the non-dimensional quantity, R. For temperatures between 5 and $25^{\circ} \mathrm{C}$ and salinities between 30 and $35 \mathrm{PSU}$, the thermal heat flux, $\alpha$, may vary between $1 \cdot 10^{-4}$ and $3 \cdot 10^{-4}$ which may also contribute to the global variation of $\log _{10}(R)$. However, along an individual front the variation in $\alpha$ is expected to be small.

The Simpson-Hunter parameter, $S=\log _{10}\left(h u^{-3}\right)$ is often used to predict the location of tidal mixing fronts for constant heat flux, $Q$. Based upon over 13,000 historical observations of $\Delta T$, Bowers and Simpson (1987) estimated that observed fronts on the Northwest European shelf (NWES) occur at a critical value $S=2.7 \pm 0.4$, with $h$ and $u$ measured in $\mathrm{m}$ and $\mathrm{m} \mathrm{s}^{-1}$, respectively. Holt and Umlauf (2008) compared the output from a regional model of the NWES to the observed location of seasonal tidal mixing fronts based upon $\sim 80,000 \Delta T$ observations from the International Council for the Exploration of the Sea (ICES, 2014, http://geo.ices.dk) and found that the mean frontal position occurred at a critical value of the Simpson-Hunter parameter, $S=3.0 \pm 0.3$.

Eq. (3) represents the Simpson-Hunter parameter with the net downward surface heat flux, $Q$, included so that the predicted location of tidal mixing fronts accounts for the differences in heat flux at different locations. The net downward heat flux, $Q$, is estimated from satellite observations and reanalysis (Liu et al., 2015).

There have been numerous studies of tidal mixing fronts in shelf seas using regional models and infrared satellite images. Studies examining tidal mixing fronts on the NWES include: Simpson and Hunter (1974), Simpson et al. (1978), Pingree and Griffiths (1978), Simpson and Bowers (1981), Bowers and Simpson (1987), Holt and Umlauf (2008), and O'Dea et al. (2012). Mixing fronts have also been studied in the Canadian arctic: Griffiths et al. (1981) studied tidal mixing fronts in Hudson Bay and Foxe Basin; Hannah et al. (2009) studied fronts in the Canadian Arctic Archipelago. Other studies of tidal mixing fronts have been conducted for the Gulf of St. Lawrence (Pingree and Griffiths, 1980; Lu et al., 2001); Gulf of Maine (Garrett et al., 1978; Loder and Greenberg, 1986); Patagonian shelf (Glorioso, 1987; Glorioso and Simpson, 1994; Glorioso and Flather, 1995; Acha et al., 2004; Luz Clara et al., 2015); South China Sea (Tong et al., 2010); Bungo Channel, Japan (Takeoka et al., 1997); and Sea of Okhotsk (Zhabin and Dubina, 2012). The above list is non-exhaustive but illustrates the prevalence of tidal mixing fronts within shelf seas around the globe.

In this paper we provide a first order assessment of HYCOM skill in replicating shelf sea tides. We compare sea surface heights to tide gauges, and to the altimeter constrained models TPXO8 (Egbert et al., 1994; Egbert and Erofeeva, 2002) and FES2014 (Carrere et al., 2016; Lyard et al., 2017 (in prep); http://www.aviso.altimetry.fr). Where velocity records are available we also compare the model barotropic tidal currents to tidal currents estimated from velocity records.

In order to provide an estimate of model bias and anomalies from 
climatological means HYCOM SST for the arctic and austral summers is compared to the 30 year seasonal averages between 1982 and 2011 of the Objectively Interpolated Sea Surface Temperatures estimated from satellite data (OISST; Reynolds et al., 2002) and also to the Multi-scale Ultra-high Resolution foundation SST (MUR SST fnd; $_{\text {; }}$ Chin et al., 2017) estimated from satellite observations between December 2011-February 2012 and June 2012-August 2012 which coincide with the period of time simulated by HYCOM.

The location of tidal mixing fronts in HYCOM is estimated in terms of the potential energy anomaly and its gradient as well as the sea surface to seabed temperature gradient. Observations of the global potential energy anomaly and global seabed temperature are difficult to obtain and for that reason the locations of the tidal mixing fronts in HYCOM are compared to horizontal gradients of the MUR $\mathrm{SST}_{\text {fnd }}$ to provide observational evidence of mixing front locations for the period of time simulated by HYCOM. We also compare tidal mixing fronts in the HYCOM simulation with tides to tidal mixing fronts reported in previous studies. Our identification of tidal mixing fronts, based upon differences in stratification and vertical temperature gradients, assumes that they result from the influx of solar radiation and from changes in stratification due to changes in the temperature field. While sea ice dynamics, including ice-melt, and freshwater influx from major rivers are included in the model we do not attempt to identify mixing fronts associated with differences in salinity. Much of our manuscript focuses on the NWES where large amounts of data, as well as a regional simulation using the Nucleus for European Modelling of the Ocean (NEMO; Madec, 2008), are available for comparison. We also provide evidence of tidal mixing fronts on the North West Australian Shelf (NWAS) which we have not been able to identify in the existing scientific literature.

In Section 2 we describe the HYCOM simulations and NEMO simulation as well as the selection of observations and data products used for comparison to the model simulations. In Section 3 we compare global HYCOM output to observations to provide an overall assessment of HYCOM skill in coastal and shelf seas. In Section 4 we take a closer look at the NWES, where we compare HYCOM skill to the skill of a regional NEMO simulation. In Section 5 we extend our study to other shelf and coastal seas to assess HYCOM skill focussing on regions with large amplitude tides where tidal mixing fronts have previously been studied. Section 5 also examines the NWAS where large amplitude tides are known to occur and yet previous studies of tidal mixing fronts over the NWAS are difficult to identify in the literature. In Section 6 we discuss our results on the skill of global HYCOM in replicating the tides and tidal mixing fronts in coastal and shelf seas.

\section{Model configuration and data selection}

The global HYCOM simulations used in this study (Ngodock et al., 2016) are configured on a tripolar grid with 41 hybrid vertical layers and $1 / 12.5^{\circ}$ horizontal resolution (approximately $8.9 \mathrm{~km}$ at the equator). Fig. 1 shows the bathymetry, but on a uniform cylindrical projection, rather than the tripole grid. HYCOM employs a time-varying vertical coordinate which consists of z-layers to represent the near surface mixed layer, terrain following coordinates in shallow water, and isopycnal coordinates in deep water.

The model employs a quadratic bottom drag formulation (Mellor, 2004) based upon the "Law of the Wall" (Schlichting, 1968) in which the drag coefficient, $C_{d}$, is specified at the grid point $(i, j)$ by:

$C_{d}^{i, j}=\max \left\{C_{d}^{\min },\left(\frac{\kappa}{\ln \left(\frac{0.5 d_{i, j}}{z_{0}}\right)}\right)^{2}\right\}$,

where $\kappa=0.4$ is the von Kármán constant, $d_{i, j}$ is the depth of the water column at grid point $(i, j), z_{o}=0.01$ is the bottom roughness in meters, and $C_{d}{ }^{\min }=2.5 \cdot 10^{-3} \cdot C_{d}$ varies from $2.5 \cdot 10^{-3}$ in waters of depth
$60 \mathrm{~m}$ or greater to $5.248 \times 10^{-3}$ at the minimum model depth of $5 \mathrm{~m}$.

HYCOM employs the K-Profile Parameterization (KPP) mixing scheme (Large et al., 1994) for vertical mixing. In addition to its surface boundary layer, KPP includes a set of additive options: a background value, shear instability, non-local mixing, and double diffusion. HYCOM does not have convective overturning and hence shear instability is the only mechanism to correct an unstable density profile. Shear instability uses locally referenced potential density (which is close to in-situ density, but each stability calculation uses only one pressure value).

Within HYCOM interior viscosity is assumed to consist of two components: 1.) contribution of resolved shear instability; 2.) contribution of unresolved shear instability due to the background internal wave field. Interior diffusivity includes both of these two contributions and also a contribution of double diffusion.

The contribution due to shear instability is parameterized in terms of the gradient Richardson number, $R i_{g}$, at layer interfaces and mixing is triggered when $R i_{g}<0.7$. The contribution of shear instability, temperature and salinity diffusivity, and viscosity are the same. For shear instability, $\mathrm{v}^{\mathrm{s}}$, the contribution is given by (Halliwell KPP Mixing Algorithm, https://hycom.org/attachments/067_kpp.pdf): $v^{\mathrm{s} /}$ $v^{0}=\left[1-\left(R i_{g} / R i_{0}\right)^{2}\right]^{3}$ when $0<R i_{g}<R i_{0}$. When $R i_{g}<R i_{0}, \mathrm{v}^{\mathrm{s}} /$ $v^{o}=1$ and when $R i_{g}>R i_{0}, \mathrm{v}^{\mathrm{s}} / v^{o}=0$; with $\mathrm{v}^{0}=50 \cdot 10^{-4}$ and $R i_{O}=0.7$. Unresolved (background) diffusivities for salinity, $\mathrm{S}$, temperature, $\mathrm{T}$, due to internal wave shear are specified as: $v_{S}{ }^{w}=v_{T}{ }^{w}=0.1 \cdot 10^{-4}$ and background viscosity is $v_{m}{ }^{w}=1.0 \cdot 10^{-4}$.

The double diffusion density ratio: $R_{\rho}=\alpha^{\partial T} / \partial z / \beta^{\partial S} / \partial z$, where $\alpha$ and $\beta$ are the expansion coefficients for temperature and salinity, is used to identify locations where double diffusive processes are important. For salt-fingering salinity diffusivity is given by: $v_{S}{ }^{d} / v_{f}=\left[1-\left(R_{\mathrm{\rho}}-1 /\right.\right.$ $\left.\left.R_{\rho}{ }^{0}-1\right)^{2}\right]^{3}$ when $1<R_{\rho}<R_{\rho}^{0}$ and $v_{S}{ }^{d} / v_{f}=0$ when $R_{\rho} \geq R_{\rho}^{0}$; temperature diffusivity is given by: $v_{T}{ }^{d}=0.7 v_{S}{ }^{d}$ where $v_{f}=10 \cdot 10^{-4}$ and $R_{\rho}{ }^{0}=1.9$. For diffusive convection, the temperature diffusivity is: $v_{T}^{d} /$ $v=0.909 \exp \left\{4.6 \exp \left[-0.54\left(R_{\mathrm{\rho}}{ }^{-1}-1\right]\right\}\right.$ where $\mathrm{v}$ is the molecular viscosity for temperature; for salinity: $v_{S}{ }^{d}=v_{T}{ }^{d}\left(1.85-0.85 R_{\rho}{ }^{-1}\right) R_{\rho}$ when $0.5 \leq R_{\rho} \leq 1$ and $v_{S}{ }^{d}=v_{T}{ }^{d}\left(0.15 R_{\rho}\right)$ when $R_{\rho}<0.5$.

At the ocean surface, the simulations included atmospheric forcing fields from the Navy Global Environmental Model (NAVGEM; Hogan et al., 2014). The HYCOM simulation with tides was forced with atmospheric fields having a horizontal resolution of $1 / 3^{\circ}$ that are output at hourly intervals. The HYCOM simulations run from July 2011 to September 2012 with the first 3 months discarded; only the period from October 2011 to September 2012 is used for analysis. The simulations are an extension of a previous HYCOM simulations initialized from climatology in 2003 and executed until 2011 using NAVGEM forcing at $1 / 2^{\circ}$ horizontal resolution at $3 \mathrm{~h}$ intervals. HYCOM is coupled with the dynamic sea-ice model CICE (Hunke and Lipscomb, 2008), and includes freshwater input from rivers (Barren and Smedstad, 2002). Our HYCOM simulations are high resolution. However they are not run long enough to get the deep water circulation into equilibrium; this is also true of most high resolution simulations that currently exist. In coastal and shelf seas, where mixing tends to be more dynamic, the model is expected to be in equilibrium and able to respond, within the limits of model resolution, to atmospheric and tidal forcing.

The two HYCOM simulations presented here differ by the addition of tidal forcing and the inclusion of an improved bathymetry under the ice shelves around Antarctica. The inclusion of ice shelves is necessary to provide accurate model tides in the Southern Ocean. Tidal forcing includes the three largest semidiurnal and two largest diurnal constituents $\mathrm{M}_{2}, \mathrm{~S}_{2}, \mathrm{~N}_{2}, \mathrm{~K}_{1}$, and $\mathrm{O}_{1}$. The tidal simulation employs tidal selfattraction and loading (SAL; Hendershott, 1972; Ray, 1998), which incorporates the effects of solid-earth deformation due to the loading of ocean tides, and the perturbations to the equipotential due to the gravitational self-attraction of both the tides and the load-deformed solid earth. In the simulations presented here, we compute the SAL term from amplitude and phase maps constructed from the TPXO Atlas. 


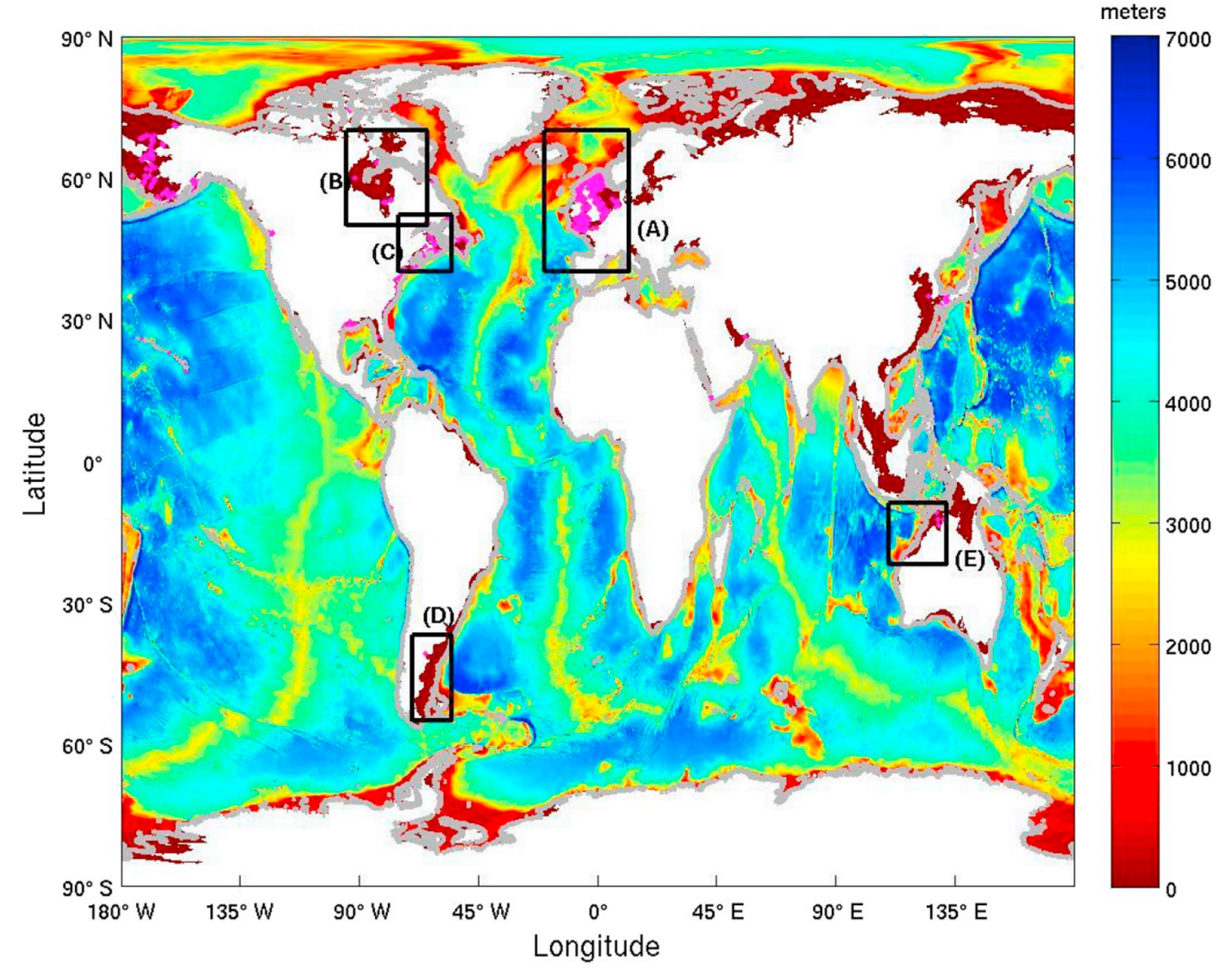

Fig. 1. HYCOM global bathymetry (meters) with the $200 \mathrm{~m}$ depth contour shown as a gray line. Locations of the available velocity records are shown as magenta dots and selected study areas are outlined with black boxes: (A) Northwest European shelf (NWES); (B) Hudson Bay and Hudson Strait (HBS); (C) Gulf of St. Lawrence and Gulf of Maine (GSLM); (D) Patagonian shelf (PS); (E) Northwest Australian shelf (NWAS).

Formulae for the SAL term can be found in, for instance, Ray (1998). The model also employs a parameterized topographic wave drag scheme (Jayne and St. Laurent, 2001) to represent the generation and breaking of high vertical mode internal waves that are unresolved due to the relatively low horizontal and vertical resolution used in the simulation (Arbic et al., 2004, 2010). The topographic wave drag scheme is only employed when the water column depth exceeds $500 \mathrm{~m}$. The tidal simulation incorporates an Augmented State Ensemble Kalman filter (ASEnKF; Ngodock et al., 2016) to reduce barotropic tidal SSH errors. The ASEnKF is used to reduce the barotropic tidal elevation errors that arise due to imperfect knowledge of ocean bathymetry and of the mechanisms that damp the tides. The ASEnKF uses an ensemble of stochastically generated correction terms to the tidal forcing. The differences between each ensemble member and TPXO are computed, and the final correction to the model is computed by minimizing the Root Mean Square Error of the ensemble members with respect to the data assimilative model TPXO. The $\mathrm{M}_{2}$ sea surface elevation error, computed equatorward of $66^{\circ}$ and over seafloor depths exceeding $1000 \mathrm{~m}$, of the HYCOM ASEnKF simulation used in this study is $2.6 \mathrm{~cm}$ compared to an elevation error of $4.4 \mathrm{~cm}$ in previous simulations which don't employ the ASEnKF (Ngodock et al., 2016).

Other than the use of the Augmented State Ensemble Kalman filter used to reduce tidal SSH errors the HYCOM simulations presented here are non-assimilative. Since these simulations do not assimilate data it may be expected that SST offshore (deep water) may be incorrect because fronts and eddies are in the wrong place and SST near shore may be incorrect because the atmospheric forcing is the major driver and is from a global Numerical Weather Prediction product on a coarse grid. Hence we may anticipate differences between SST in HYCOM compared to climatological datasets and satellite SST products.
The NEMO simulation of the NWES (O'Dea et al., 2012) has horizontal resolution of $1 / 9^{\circ}$ in longitude and $1 / 15^{\circ}$ in latitude. The vertical coordinate is hybrid s- $\sigma$ with 32 layers. Temperature and salinity are initialized from the UK Met Office Forecasting Ocean Assimilation Model (FOAM) $1 / 12^{\circ}$ system (Martin et al., 2007) and started from a rest state. The model spins up for 1 year (Nov. 2006-Oct. 2007), is reinitialized with the output of the first year, and repeated for a second year. The simulation is then restarted from Nov. 2006, initialized from the end of the second spin up year, and the simulation runs from Nov. 2006 to the end of 2008. Analysis of model output is done using the last 2 model years 2007-2008. Model bathymetry is derived from the North-West Shelf Operational System (NOOS) bathymetry. Atmospheric forcing and surface fluxes are derived from the global UK Met Office Numerical Weather Prediction model. In addition to specification of the equilibrium tide, tidal forcing also includes 15 tidal constituents estimated from a North-East Atlantic tide model (Flather, 1976, 1981) at the boundaries. Boundary conditions for temperature and salinity are provided through a relaxation scheme in which the scalar fields are relaxed towards values specified by the UK Met Office operational FOAM $1 / 12^{\circ}$ deep ocean model for the North Atlantic (Storkey et al., 2010).

Current meter data from the British Oceanographic Data Centre (BODC, http://bodc.ac.uk) and the Global Multi-Archive Current Meter Database (GMACMD, Scott and Furnival, 2013) were selected subject to the following criteria for comparison to model data:

1.) Water column depth less than or equal to $200 \mathrm{~m}$;

2.) Signal length of at least 30 days;

3.) Instrument depth at least $10 \mathrm{~m}$ from the sea surface and at least $10 \mathrm{~m}$ above the sea floor. 
Each velocity record was analysed using harmonic tidal analysis (Foreman, 1977, 1978; Pawlowicz et al., 2002). For each tidal constituent only those estimates with a signal to noise ratio $>2$ were retained for comparison to model values. A combined total of 3409 velocity records from the BODC and GMACMD, spanning the years 1968 to 2010 , were found to satisfy the above three criteria while also having a signal to noise ratio greater than or equal to 2 for the $\mathrm{M}_{2}$ constituent. Tidal ellipse parameters for depth averaged currents estimated from Acoustic Doppler Current Profilers (ADCP's), lying in water less than or equal to $200 \mathrm{~m}$ depth, on the North West Australian Shelf (Cancet et al., 2017) were also included, as were tidal ellipse parameters provided in Holloway (2001) for constituents $\mathrm{M}_{2}$ and $\mathrm{S}_{2}$. The ADCP's on the North West Australian Shelf are part of the Australian ADCP network (IMOS, 2017). Of the 4 current meters of Moreira et al. (2009) only 1 was in water deeper than $10 \mathrm{~m}$. This observation was included and provides the only estimate of observed tidal currents on the Patagonian Shelf in this study. In total 3432 observations of tidal currents were used in this study.

The meteorological boreal summer (JJA) represents those months during which the incident solar radiation is at a maximum in the northern hemisphere while the austral summer (boreal winter; DJF) represents those months during which the incident solar radiation is at a maximum in the southern hemisphere. The choice of meteorological seasons aligns our study with previous studies of tidal mixing fronts which, in the northern hemisphere, typically form in May and dissipate in September. For comparison with previous studies the vertical temperature gradient, $\Delta T$, estimated from monthly mean Sea Surface Temperatures (SST) and Seabed Temperatures (SBT) from HYCOM for the model years 2011-2012 was also calculated.

The potential energy anomaly, $\varphi$, for each of the study regions is estimated by vertically integrating the 3-dimensional monthly mean temperature and salinity fields from HYCOM for the model years 2011-2012. The monthly mean fields of $\varphi$ are then averaged over time to provide seasonal values representing northern hemisphere winter months: December, January, February (DJF) and summer months: June, July, August (JJA). Horizontal gradients of the potential energy anomaly are calculated from the seasonal values to provide estimates of frontal locations defined by $|\nabla \varphi|>2.5 \cdot 10^{-4}$ and $\varphi<10 \mathrm{~J} \mathrm{~m}^{-3}$.

Estimates of the potential energy anomaly and its gradient are not available from observational data on a global scale. Hence we have chosen to compare the location of tidal mixing fronts in HYCOM to gradients of foundation SST values which are free of diurnal fluctuations due to day time incoming solar radiation. The MUR SST $_{\text {fnd }}$ (Chin et al., 2017) from December 2011 through February 2012 and June 2012 through August 2012 were selected for comparison to HYCOM and interpolated onto the HYCOM grid. MUR SST $\mathrm{Snd}_{\text {fnd }}$ values and HYCOM SST values from both simulations with and without tides values are also area averaged onto the $1 / 4^{\circ}$ grid for comparison to the seasonal values of the OISST dataset. On the NWES we also compare HYCOM to output from a non-assimilative regional NEMO simulation (O'Dea et al., 2012) and to the ICES SST-SBT observational climatology prepared by Holt and Umlauf (2008). Seasonal averages for the net downwards surface heat flux, $Q$, estimated from satellite observations and reanalysis (Liu et al., 2015) are interpolated to the model grids to predict the location of tidal mixing fronts using the parameter, $S_{Q}$, given by Eq. (3).

\section{HYCOM performance in global shelf seas}

For this study we define the global coastal and shelf seas as those regions of the global ocean with a depth $<200 \mathrm{~m}$. Fig. 1 shows the global HYCOM bathymetry with the $200 \mathrm{~m}$ bathymetric contour depicted by a gray line. The locations of the current meters and the regional study areas discussed in this paper are also displayed on Fig. 1.

The Root Mean Square Error (RMSE) between model values and tide gauge observations of SSH may be calculated using tidal amplitude and phase:

$$
\begin{aligned}
& \operatorname{RMSE}_{S S H}^{\text {gauge }}(\text { model }) \\
& \quad=\sqrt{\frac{\sum_{n=1}^{N}\left[\frac{1}{2}\left(a_{n}^{\text {model }}-a_{n}^{\text {gauge }}\right)^{2}+a_{n}^{\text {model }} a_{n}^{\text {gauge }}\left(1-\cos \left(\theta_{n}^{\text {model }}-\theta_{n}^{\text {gauge }}\right)\right)\right]}{N},},
\end{aligned}
$$

where $a_{n}^{\text {gauge }}$ and $\theta_{n}{ }^{\text {gauge }}$ represent the amplitude and phase of a given tidal constituent estimated from the $\mathrm{n}^{\text {th }}$ of $\mathrm{N}$ tide gauges and $a_{n}{ }^{\text {model }}$ and $\theta_{n}{ }^{\text {model }}$ represent the amplitude and phase values estimated from the nearest model grid point.

When compared to the global set of shelf sea tide gauges used by Stammer et al. (2014) RMSE gauge (TPXO), RMSE $E_{S S H}^{\text {gauge }}$ (FES2014), and $R M S E_{S S H}^{\text {gauge }}(H Y C O M)$ values for constituent $\mathrm{M}_{2}$ are 3.6, 3.7 and $24.1 \mathrm{~cm}$, respectively. $R M S E_{S S H}^{\text {gauge }}$ for constituents $\mathrm{S}_{2}, \mathrm{~N}_{2}, \mathrm{~K}_{1}$, and $\mathrm{O}_{1}$ compared to the global set of shelf sea tide gauges may be found in the online supplementary information (Table S1).

The area-weighted Root Mean Square Errors between HYCOM and the altimeter constrained models TPXO and FES2014 is:

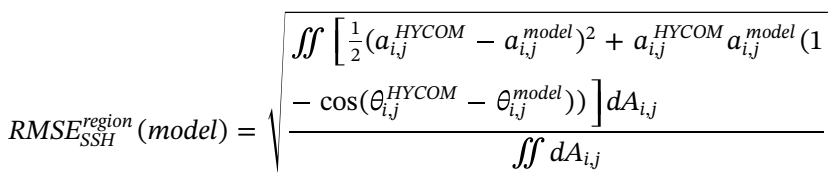

and the area-weighted amplitude Mean Errors (ME) is:

$M E_{S S H}^{\text {region }}($ model $)=\frac{\iint\left(a_{i, j}^{H Y C O M}-a_{i, j}^{\text {model }}\right) d A_{i, j}}{\iint d A_{i, j}}$,

where region is an identifier for the region (in some cases, Global) being analysed; model is used to identify either TPXO or FES2014; and $a_{i, j}, \theta_{i, j}$, and $d A_{i, j}$ are the amplitude, phase, and area, respectively, of the grid cell indexed by $i, j$. HYCOM, TPXO8, and FES2014 are interpolated to a common grid prior to calculating the RMSE and ME. Shelf seas contain both micro- and macro-tidal regions and hence area-weighted RMSE and ME do not necessarily reflect the true model error at a particular location. However such statistics do provide a general indicator of model performance over a large geographic region. Model performance at a particular site may differ significantly from the area-weighted statistic.

Over the global coastal and shelf seas $R M S E_{S S H}^{\text {Global }}$ (TPXO8) and $R M S E_{S S H}^{G l o b a l}$ (FES2014) for $\mathrm{M}_{2}$ are $17.4 \mathrm{~cm}$ and $17.3 \mathrm{~cm}$, respectively. Compared to the root mean squared amplitude of $\sim 50 \mathrm{~cm}$ for the global shelf and shelf seas (depth $<200 \mathrm{~m}$ ) of all three models, $R M S E_{S S H}^{G l o b a l}$ represents an error of $\sim 35 \%$. Estimates of $M E_{S S H}^{G l o b a l}(T P X O 8)$ and $M E_{S S H}^{G l o b a l}$ (FES2014) for $\mathrm{M}_{2}$ are $-0.6 \mathrm{~cm}$ and $-1.6 \mathrm{~cm}$, respectively, indicating that on average HYCOM $\mathrm{M}_{2}$ amplitudes are slightly smaller than both of the altimetry constrained models over the global and coastal shelf seas. Details of the $R M S E_{S S H}^{G l o b a l}$ and $M E_{S S H}^{G l o b a l}$ values for the other constituents may be found in the online supplementary information (Table S2).

For tidal currents, the equivalent metric for the root mean square error for tidal heights (Eq. (5)) is:

$R M S E_{\text {ellispe }}^{\text {region }}($ model $)=\sqrt{\frac{\sum_{n=1}^{N}\left[D_{u}^{n}(\text { model })\right]^{2}}{N}}$

where:

$$
\begin{aligned}
D_{u}^{n}(\text { model })= & {\left[\frac{1}{2}\left(a_{o}^{n 2}+b_{o}^{n 2}+a_{m}^{n 2}+b_{m}^{n 2}\right)\right.} \\
& -\cos \left(g_{o}^{n}-g_{m}^{n}\right) \cos \left(\theta_{o}^{n}-\theta_{m}^{n}\right)\left(a_{o}^{n} a_{m}^{n}\right. \\
& \left.\left.+b_{o}^{n} b_{m}^{n}\right)-\sin \left(g_{o}^{n}-g_{m}^{n}\right) \sin \left(\theta_{o}^{n}-\theta_{m}^{n}\right)\left(a_{o}^{n} b_{m}^{n}+a_{m}^{n} b_{o}^{n}\right)\right]^{1 / 2}
\end{aligned}
$$

is the Root Mean Square Difference between the $\mathrm{n}^{\text {th }}$ tidal ellipse 
estimated from the model (subscript $\mathrm{m}$ ) and observed (subscript o) current velocity (Cummins and Thupaki, 2018). The variable model is used to indicate one of HYCOM, TPXO8, or FES2014 and region represents the study area (in some cases Global). In Eq. (8b): a and b are the semi-major and semi-minor axis of the tidal ellipses, respectively; $g$ and $\Theta$ are the Greenwich Phase Lag and inclination of the tidal ellipses, respectively. Over $\mathrm{N}$ observations the root mean squared current ellipse magnitude is given by:

$R M S_{\text {ellipse }}^{\text {Global }}=\sqrt{\frac{\sum_{n=1}^{n=N} \frac{1}{2}\left(a_{o}^{n^{2}}+b_{o}^{n^{2}}\right)}{N}}$,

and the relative error is:

$D_{\text {ellipse }}^{\text {rel }}=100 \frac{R M S E_{\text {ellipse }}}{R M S_{\text {ellipse }}}$.

For the global set of current meter observations, $D_{\text {ellipse }}^{\text {rel }}($ model $)=64$, 57 and $55 \%$ for the barotropic $\mathrm{M}_{2}$ tidal current in the models: HYCOM, TPXO8 and FES2014, respectively compared to the root mean squared ellipse magnitude $R M S_{\text {ellipse }}=21.8 \mathrm{~cm} \mathrm{~s}^{-1} . R M S E_{\text {ellipse }}^{\text {Global }}$ (model) and $R M S_{\text {ellipse }}^{\text {Global }}$ for the barotropic $\mathrm{M}_{2}, \mathrm{~S}_{2}, \mathrm{~N}_{2}, \mathrm{~K}_{1}$, and $\mathrm{O}_{1}$ tidal currents are provided in the online supplementary information (Table S3). The insitu current meter observations do not necessarily represent the barotropic tidal current. However, on average, the observed kinetic energy may be expected to lie close to the barotropic kinetic energy. As previously discussed in Timko et al. $(2012,2013)$ the low vertical resolution of the discrete current meter observations on the moorings identified (typically 3 or less instruments per mooring) in the GMACMD typically does not allow for the barotropic tidal currents to be estimated from the observations. The non-stationarity of coastal tidal currents (Nash et al., 2012) may also play a role in the relatively poor comparison, especially because some of the coastal observations are of short duration, and are sampled over a wide range of times. Internal tides propagating onto the shelf within the global HYCOM simulation may also significantly change the vertical profile (Gerkema et al., 2004; Katavouta and Thompson, 2016; Kodaira et al., 2016).

Regression analysis between the barotropic tidal kinetic energy in models and current meter observations (Fig. 2) indicates that overall HYCOM $\mathrm{M}_{2}$ barotropic tidal kinetic energy lies somewhat closer to the observations than both TPXO8 and FES2014. The regression coefficient, A, between HYCOM and the observed tidal kinetic energy is $A_{\text {HYCOM }}=0.99$ compared to $A_{\text {TPXO }}=0.82$ and $A_{F E S}=0.81$ for TPXO8 and FES2014, respectively.

Global $\mathrm{M}_{2}$ tidal energy dissipation rates due to bottom friction are given by $D=\iint C_{d} \rho\left\langle u^{3}\right\rangle d A$ where $C_{d}$ is the bottom drag coefficient given by Eq. (4), $\rho=1030 \mathrm{~kg} \mathrm{~m}^{-3}$ is the water density (assumed constant), $\left\langle u^{3}\right\rangle$ is the cube of the $\mathrm{M}_{2}$ tidal velocity averaged over a tidal period, and $d A$ is the area. Estimates of the $\mathrm{M}_{2}$ tidal energy dissipation over global coastal and shelf seas between 10 and $200 \mathrm{~m}$ depth for the HYCOM simulation were $D=998 \mathrm{GW}$ compared to the TPXO8 $\mathrm{M}_{2}$ tidal energy dissipation rate of $1545 \mathrm{GW}$. The difference in our estimation of the global tidal energy dissipation in TPXO8 and that of Egbert and Ray (2003) may be attributed to the differences in the regions used to estimate the integral and our use of a variable $C_{d}$ for depths $<60 \mathrm{~m}$. Egbert and Ray (2001) delineated particular regions rather than using a depth contour and also assumed a constant value $C_{d}=0.003$. Buijsman et al. (2015) previously reported that HYCOM dissipation rates fell within the range of TPXO dissipation rates (Egbert and Ray, 2001). However, it appears that in this particular HYCOM simulation the total energy dissipation due to bottom friction in the global coastal and shelf seas is less than total energy dissipation estimated from TPXO8.

Differences between the HYCOM simulations with and without tides indicate that the additional mixing resulting from tidal forcing does impact model SST in the coastal and shelf seas (Fig. 3). The differences are noticeable on the Patagonian Shelf and the North West Australian

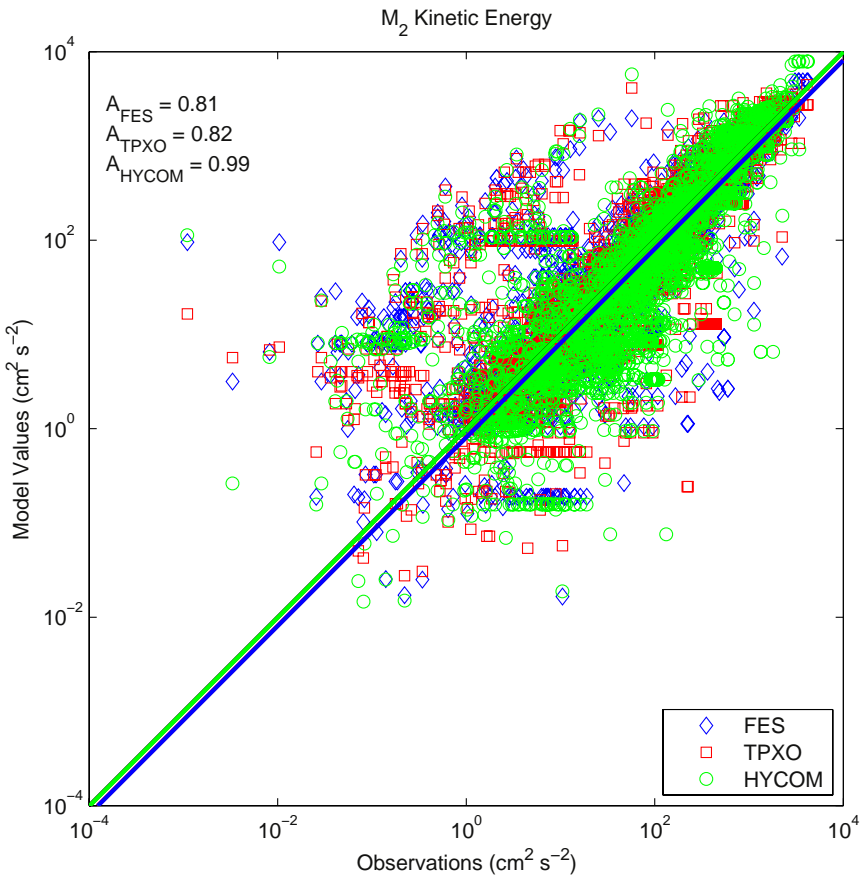

Fig. 2. Regression analysis for model barotropic $M_{2}$ tidal kinetic energy in HYCOM, TPXO8 and FES2014 vs. the $\mathrm{M}_{2}$ tidal kinetic energy estimated from the global set of current meter observations that lie in the global coastal and shelf seas. All current meter observations lie within regions where water column depth is less than or equal to $200 \mathrm{~m}$.

Shelf during DJF and in Hudson Bay and Hudson Strait, on the Scotian Shelf, Newfoundland Shelf and the North West European Shelf during JJA. Large differences also appear in the high Arctic during JJA. Internal tides may also contribute to the differences in SST. However, in a study analysing the impact of horizontal resolution on simulations of the North West European Shelf Guihou et al. (2018) found that at model resolutions of $\sim 7 \mathrm{~km}$ and at $1 / 12^{\circ}$ internal tide propagation onto and over the shelf regions was not fully resolved when compared to a $1 / 60^{\circ}$ simulation. Within the $1 / 12^{\circ}$ global HYCOM simulations presented in this manuscript we anticipate that internal tides over the shelf regions are also unlikely to be fully resolved, and may therefore contribute only in minor ways to the differences in SST over the shelf seas.

Seasonal averages from DJF and JJA of HYCOM SST and MUR $\mathrm{SST}_{\text {fnd }}$ values were interpolated to the $1 / 4^{\circ}$ grid of the OISST dataset using an area-weighted average. Root Mean Square Errors, $\operatorname{RMSE}_{S S T}^{\text {Global }}\left(T_{O I S S T / M U R}^{\text {HYCOM }}\right)$, and Mean Errors, $M E_{S S T}^{\text {Global }}\left(T_{O I S S T / M U R}^{H Y C O M}\right)$, between HYCOM SST and the SST fields derived from satellite observations: OISST and MUR SST $\mathrm{fnd}_{\text {fnd }}$, were estimated for the global coastal and shelf seas (depth $<200 \mathrm{~m}$ ) between $60^{\circ} \mathrm{S}$ and $70^{\circ} \mathrm{N}$ (Fig. 4). The decision to limit that latitudinal extent was made to minimize differences in the representation of sea ice between HYCOM, OISST, and MUR data. It is apparent that some bias exists in the non-assimilative HYCOM simulations and that embedding tides in HYCOM has a mixed impact on the global RMSE and ME values compared to satellite observations. The inclusion of tides in HYCOM decreases $R M S E_{S S T}^{\text {Global }}\left(T_{O I S S T}^{H Y C O M}\right)$ and $M E_{S S T}^{\text {Global }}\left(T_{O I S S T}^{\text {HYCOM }}\right)$ by $\sim 0.1{ }^{\circ} \mathrm{C}$ indicating a smaller error compared to the climatology. However, in JJA RMSE $E_{S S T}^{\text {Global }}\left(T_{M U R}^{H Y C O M}\right)$ and $M E_{S S T}^{\text {Global }}\left(T_{M U R}^{H Y C O M}\right)$ increase in magnitude by $\sim 0.2{ }^{\circ} \mathrm{C}$, when tides are included, indicating a departure from the observed SST during the summer months of 2012.

\section{HYCOM skill on the Northwest European Shelf (NWES)}

The NWES is a region of the world's oceans for which comprehensive observations, and numerous modelling studies, exist. As such it is possibly the best location to assess HYCOM performance in a specific 

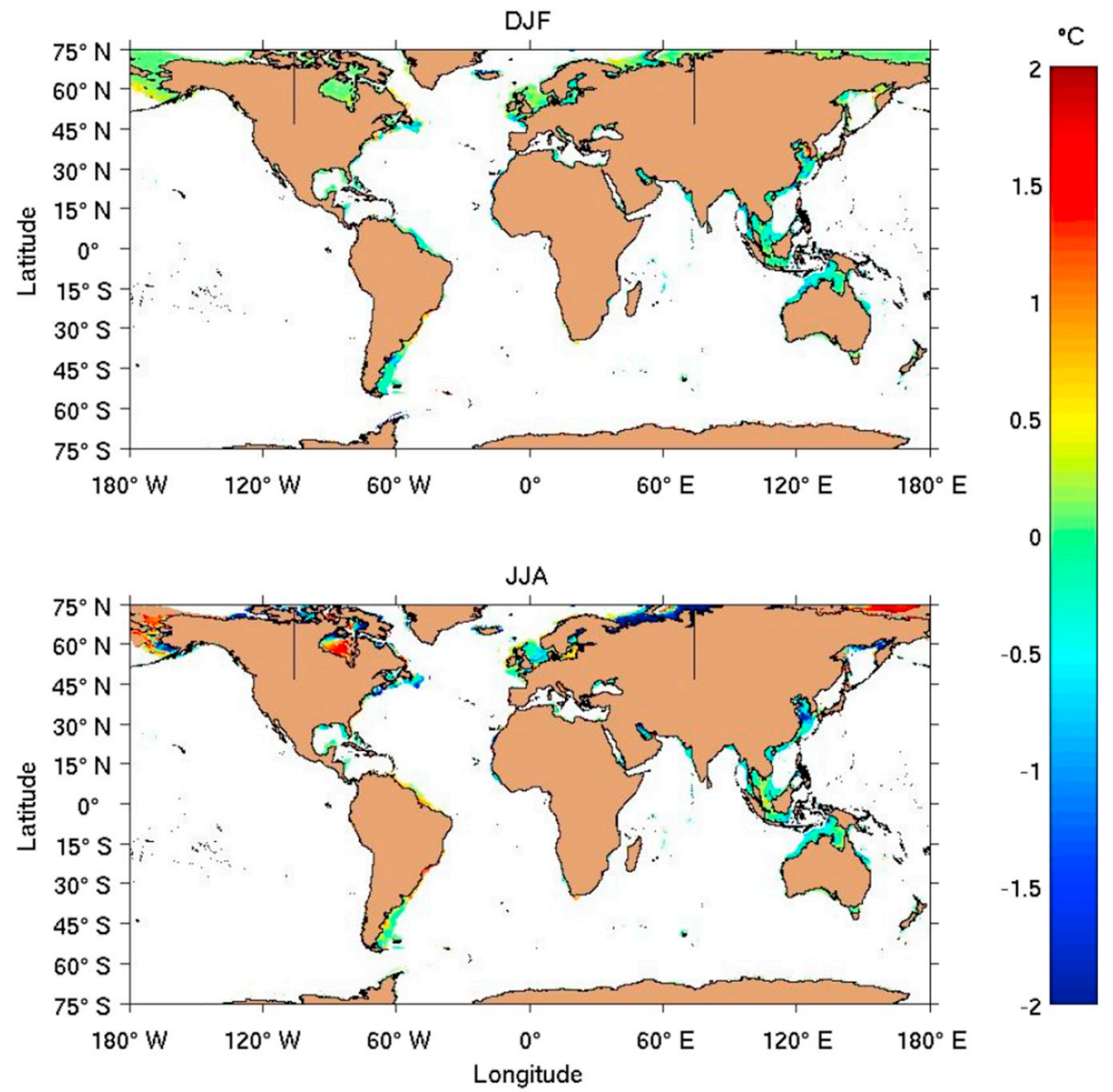

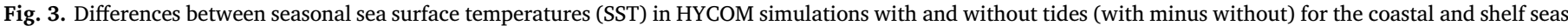
with depth less than or equal to $200 \mathrm{~m}$. The temperature scale $\left({ }^{\circ} \mathrm{C}\right)$ is shown on the right-hand side.
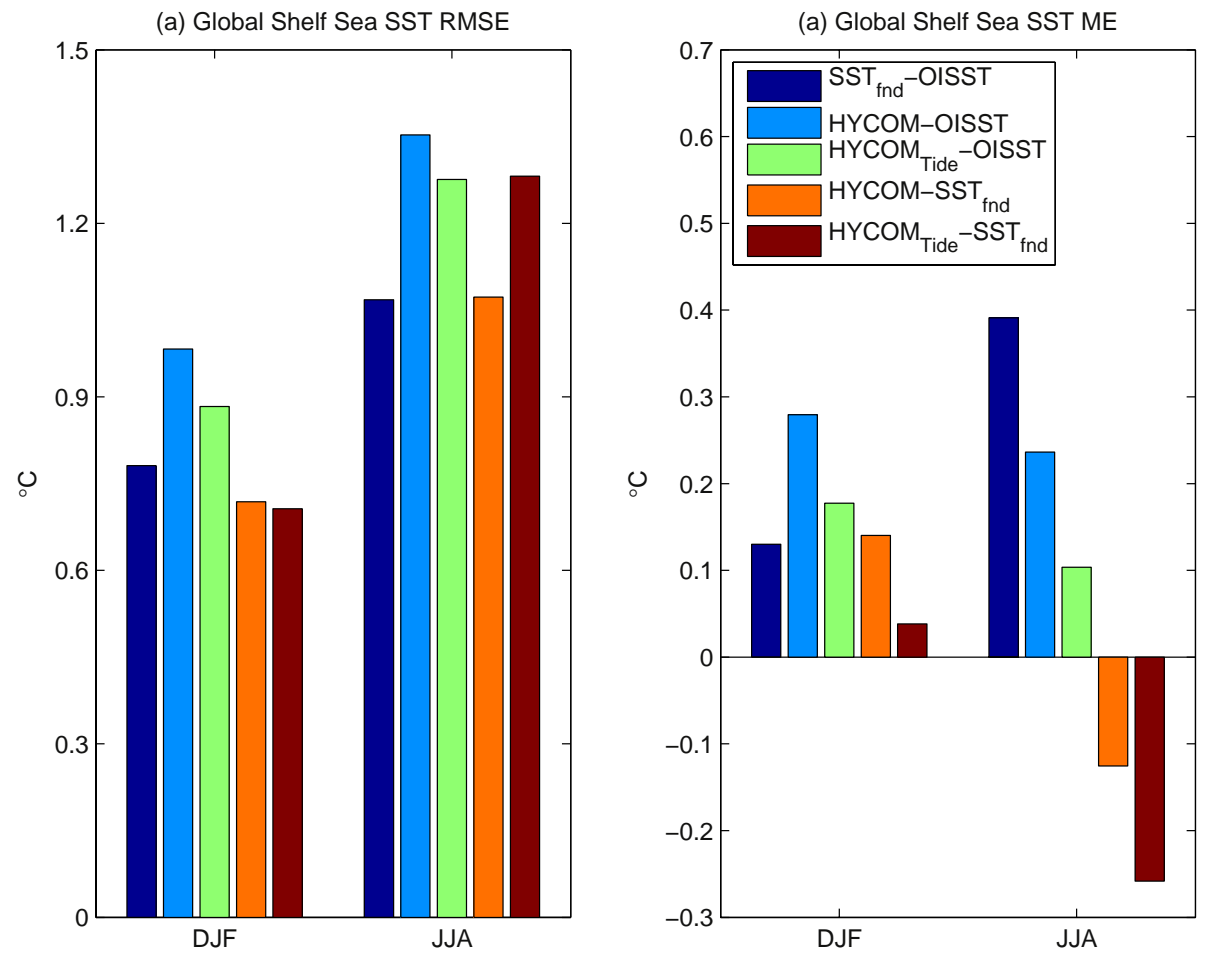

Fig. 4. Root Mean Square Error, RMSE, (panel a) and Mean Error, ME, (panel b) between HYCOM SST and OISST (Reynolds et al., 2002) and MUR SSTfnd (Chin et al., 2017). RMSE and ME are estimated over the global coastal and shelf seas with depth $<200 \mathrm{~m}$. 
shelf sea. Egbert and Ray (2001) estimated total $\mathrm{M}_{2}$ tidal energy dissipation on the NWES to be D $=203-208 \mathrm{GW}$ and we find that between depths of 10 and $200 \mathrm{~m}$ the dissipation due to bottom friction is $\mathrm{D}=212 \mathrm{GW}$ in TPXO8.1 compared to $\mathrm{D}=254 \mathrm{GW}$ in HYCOM.

Compared to the tide gauges used in Stammer et al. (2014) $\operatorname{RMSE}_{S S H}^{\text {gauge }}(H Y C O M)=26.5 \mathrm{~cm}$ for constituent $\mathrm{M}_{2}$ is 7-8 times greater than $R M S E_{S S H}^{\text {gauge }}(T P X O 8)=3.8$ and $\operatorname{RMSE}_{S S H}^{\text {gauge }}(F E S 2014)=3.4 \mathrm{~cm}$, respectively, and $>2$ times greater than $R M S E_{S S H}^{\text {gauge }}(N E M O)=12.9 \mathrm{~cm}$. Area-weighted errors: $R M S E_{S S H}^{N W E S}$ and $M E_{S S H}^{N W E S}$ represent relative errors of $27-28 \%$ and $1-2 \%$, respectively, compared to the root mean squared $\mathrm{M}_{2}$ tidal amplitude of $\sim 80 \mathrm{~cm}$. Details of the RMSE, ME, and root mean squared amplitudes for $\mathrm{M}_{2}$ and other constituents is provided in the online supplementary information (Tables S4 and S5).

For constituent $\mathrm{M}_{2}, 973$ velocity records satisfying our selection criteria and having a signal to noise ratio $>2$ were identified on the NWES with most of these records part of the BODC archive. For the barotropic $\mathrm{M}_{2}$ tidal currents, $D_{\text {ellipse }}^{\text {rel }}=41-52 \%$. The $\mathrm{M}_{2}$ tidal kinetic energy in HYCOM indicates that HYCOM is more energetic than both TPXO8 and FES2014 compared to the observed $\mathrm{M}_{2}$ tidal kinetic energy. Details of the comparison of constituent $\mathrm{M}_{2}$ and other tidal constituents and the $\mathrm{M}_{2}$ tidal energetics between HYCOM, NEMO, TPXO, and FES2014 are available in the supplementary material accompanying the online version of this paper (Table S6 and Fig. S1).

Differences in SST between the HYCOM simulations with and without tides indicate that the additional tidal forcing produces SST signatures that vary from the non-tidally forced model by as much as $2{ }^{\circ} \mathrm{C}$ (Fig. 5). When tides are included in the HYCOM simulation SST is cooler in the Irish Sea, along the southern coastline of the English Channel, and in the southern North Sea. SST is warmer on the west coast of Ireland and Scotland and also along the northern coast of the English Channel. In JJA and over water columns of depths $<200 \mathrm{~m}$
$R M S E_{S S T}^{N W E S}\left(T^{H Y C O M}\right)$ and $M E_{S S T}^{N W E S}\left(T^{H Y C O M}\right)$ are $0.1-0.2^{\circ} \mathrm{C}$ lower than $R M S E_{S S T}^{N W E S}\left(T^{H Y C O M}\right)$ for the HYCOM simulation without tides (Fig. S2 in online supplementary information). The two HYCOM simulations have identical solar heat input. Locations where the SST appears warmer between the simulations with and without tides are most likely the result of the displacement of sea surface thermoclines or eddies due to the addition of tidal forcing. The simulations do not assimilate sea surface temperature and hence the location of thermoclines and eddies evolve in response to the model physics.

As discussed in the introduction, tidal mixing fronts occur when buoyancy production is balanced by mixing in shelf seas. To allow comparison to the previous study of Holt and Umlauf (2008) and O'Dea et al. (2012) we define the location of the mixing front using the surface to seabed temperature gradient, of $\Delta \mathrm{T}=0.5^{\circ} \mathrm{C}$. For the purposes of comparison we will limit our discussion to the Flamborough Head and Dogger Bank fronts in the North Sea, the Ushant front in the English Channel, The Celtic Sea front lying outside the mouth of St. Georges Channel, the Western Irish Sea front, and the Islay-Malin Head front outside the North Channel of the Irish Sea.

Fig. 6 shows the location of the JJA mixing fronts $(\Delta T=0.5)$ together with the contour of $S_{Q}$ that lies closest (in terms of mean distance) to the mixing front locations on the NWES. Sea surface to seabed temperature gradients and the semi-major axis values of the barotropic $\mathrm{M}_{2}$ tidal currents from the HYCOM simulations were used in the calculations of $\Delta T$ and $S_{Q}$. Sea surface to seabed temperature gradients from the NEMO simulation of O'Dea et al. (2012) and the ICES set used by Holt and Umlauf (2008), were used to calculate $\Delta T$ and then combined with the barotropic $\mathrm{M}_{2}$ tidal currents from TPXO8 to estimate $S_{\mathrm{Q}}$. In the following description of the mixing fronts on the NWES the reader should refer to Fig. 8 in Belkin et al. (2009) for identification of the fronts and their approximate locations.

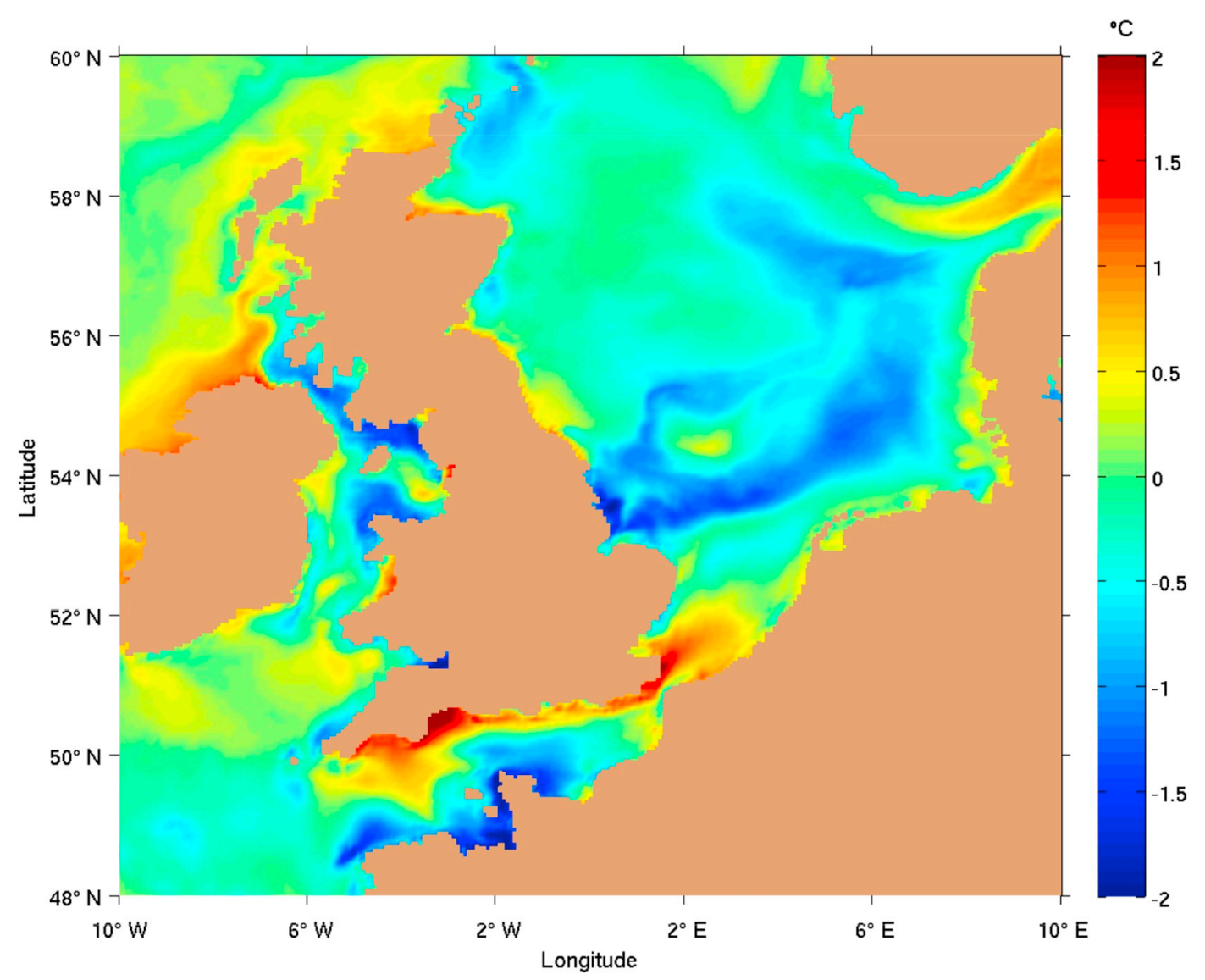

Fig. 5. Differences in SST over the NWES in summer (JJA) between the HYCOM simulation with tides minus the HYCOM simulation without tides. Temperature scale $\left({ }^{\circ} \mathrm{C}\right)$ is shown on the right-hand side. 

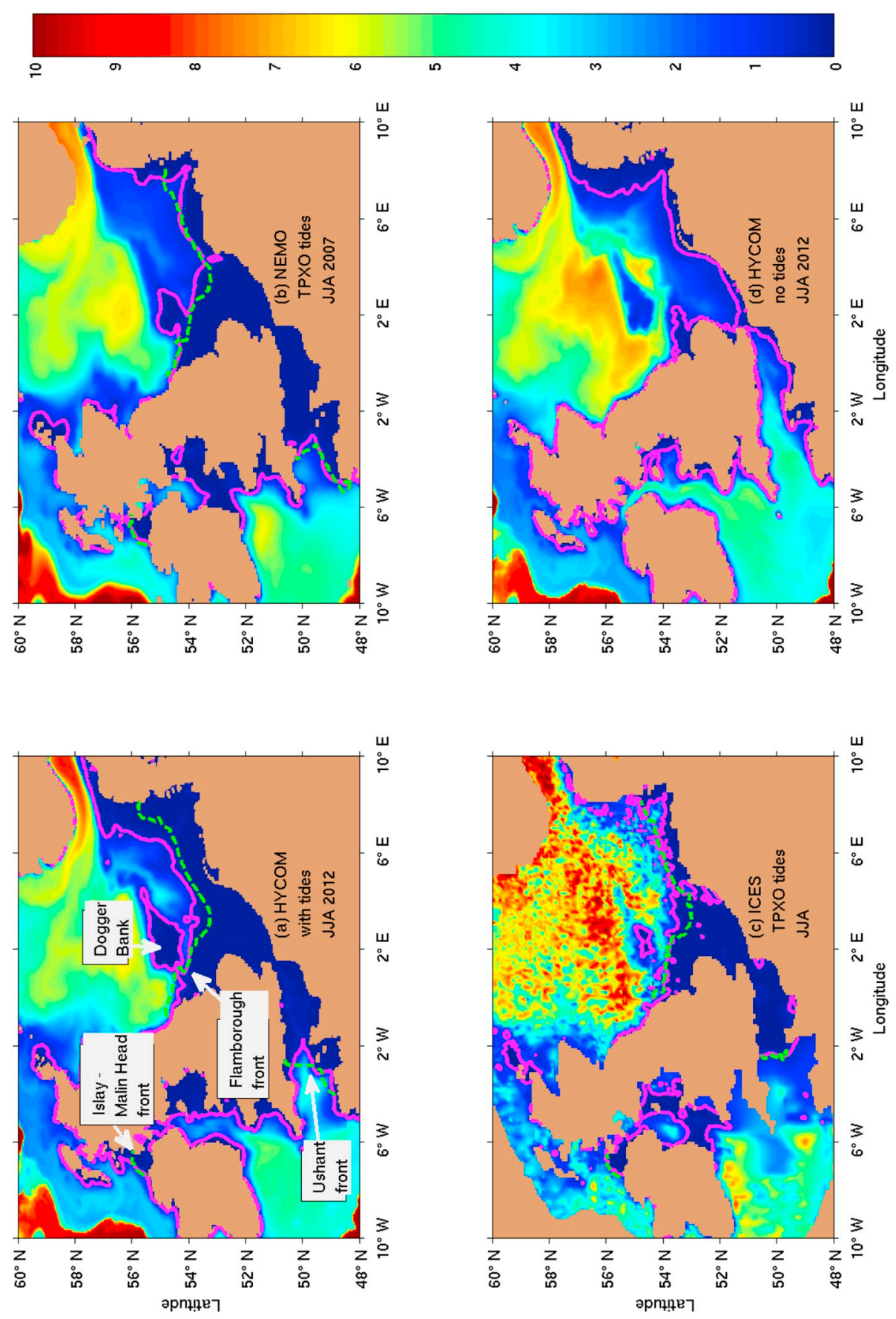

Fig. 6. Tidal mixing front representation for the NWES. Each subplot shows the JJA temperature difference between SST and SBT in: (a) HYCOM with tides; (b) NEMO; (c) ICES; and (d) HYCOM with no tides. The $\Delta \mathrm{T}=0.5^{\circ} \mathrm{C}$ contour is shown as a magenta line. The $\mathrm{S}_{\mathrm{Q}}=$ constant contour (green line) that has the minimum mean distance from the tidal mixing front contour is also shown on subplots (a)-(c). The value of $\mathrm{S}_{\mathrm{Q}}$ is estimated in subplot (b) using HYCOM tides and using TPXO8 tides in subplots (b) and (c). Temperature scale $\left({ }^{\circ} \mathrm{C}\right)$ is shown on the right-hand side.

Comparing the two HYCOM simulations with and without tides it is very clear that the addition of tides in HYCOM produces tidal mixing fronts that match some of the tidal mixing fronts seen in ICES and NEMO. These fronts do not appear in the HYCOM simulation with no tides where the zone of well mixed water is restricted near the coastlines. The bathymetry in both HYCOM and NEMO on the NWES are similar, although differences are apparent (Fig. S3 in online supplementary information), with major bathymetric features well represented in both models.

In HYCOM with tides, the Flamborough Head front $\left(S_{Q}=4.8\right)$ is well represented although it lies somewhat north of its location in $\operatorname{NEMO}\left(S_{Q}=4.6\right)$ and ICES $\left(S_{Q}=4.4\right)$. It also appears to swing to the north around $7^{\circ} \mathrm{E}$ and extends into the Skagerrak Strait. Compared to the study of Belkin et al. (2009) HYCOM with tides shows the Flamborough Head Front and the Dogger Bank Front almost merging; similar to their appearance in NEMO. In HYCOM the Flamborough Head Front appears to merge with the Frisian Front and the Danish Front, and then extend to the southern extreme of the Norwegian Coastal Current Front.

The HYCOM Ushant front $\left(S_{Q}=3.9\right)$ extends across the English Channel to the western tip of Normandy similar to its location in the ICES $\left(S_{Q}=3.4\right)$ dataset but east of its location in NEMO $\left(S_{Q}=4.4\right)$. Both the Celtic Sea front and western Irish Sea front appear in both the NEMO simulation and ICES dataset. These fronts do not appear in the HYCOM simulation with tides. The western Irish Sea front in HYCOM 


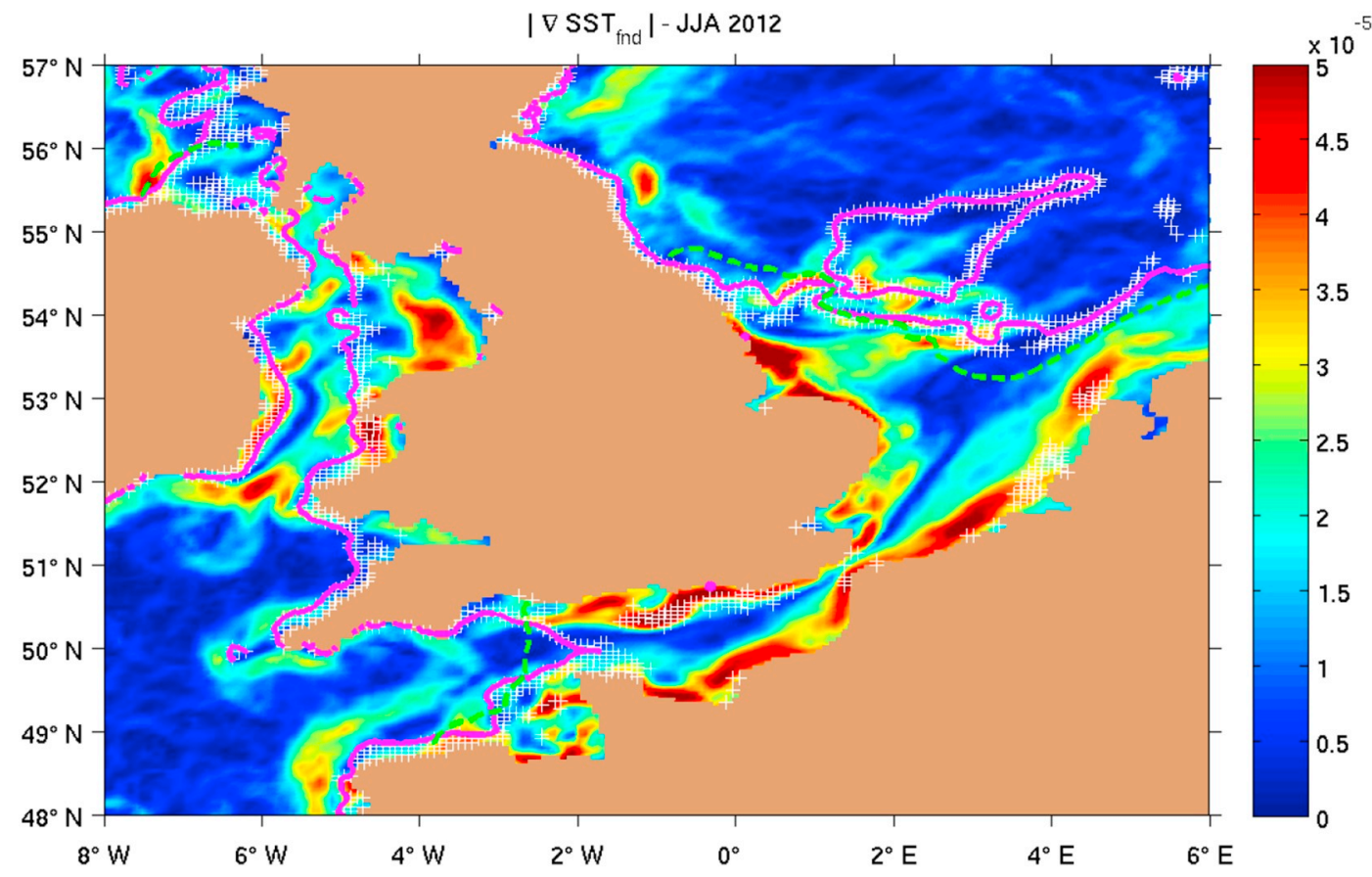

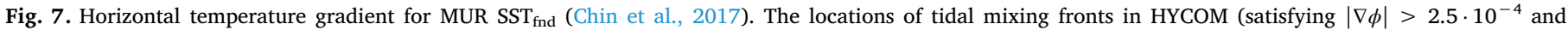
$\phi<10 \mathrm{~J} \mathrm{~m}^{-3}$ ) are indicated by white '+' producing thatched regions. The magenta line indicates the location of the $\Delta \mathrm{T}=0.5^{\circ} \mathrm{C}$ (SST $-\mathrm{SBT}$ ) contour in HYCOM. The dashed green lines indicates the location of the contour $\mathrm{S}_{\mathrm{Q}}=$ constant that has minimum mean distance to the mixing front location (see Table 1 for the values of $\left.\mathrm{S}_{\mathrm{Q}}\right)$.

appears to be weakly stratified with a mixing front extending from the south western tip of Wales to the Isle of Man and then on to the southwest tip of Scotland. The Islay - Malin Head front lies in approximately the same position in HYCOM $\left(S_{Q}=4.7\right)$ as it does in the combined NEMO - TPXO $\left(S_{Q}=4.8\right)$ and ICES - TPXO $\left(S_{Q}=4.3\right)$ data.

Fig. 7 shows a comparison between the horizontal gradient of the

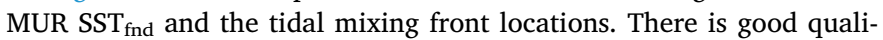
tative agreement between the mixing front locations defined in terms of the sea surface to sea bed temperature gradient: $\Delta T=0.5^{\circ} \mathrm{C}$ (magenta lines), and mixing front locations defined in terms of the potential energy anomaly: $|\nabla \phi|>2.5 \cdot 10^{-4}$ and $\phi<10 \mathrm{~J} \mathrm{~m}^{-3}$ (white thatched regions). Fig. 7 reveals relatively good agreement between the locations of the Islay-Malin Head Front in the North Channel and the Flambor-

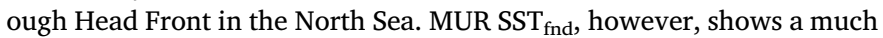
weaker frontal region lying over Dogger Bank. The HYCOM Ushant Front, in the English Channel, appears eastwards of the location in the MUR SST $_{\text {fnd }}$.

Foundation SST is the temperature of the water column free of diurnal temperature variability. In the absence of a diurnal signal foundation SST is equal to the subskin SST. It represents the temperature from which the diurnal thermocline develops each day. The daily averaged temperature fields from the HYCOM simulation do not allow for the calculation of foundation SST from the HYCOM simulation. As a proxy we have chosen temperature at $10 \mathrm{~m}$ depth for comparison; we expect temperatures at $10 \mathrm{~m}$ depth to be free of most diurnal temperature variations caused by daytime heating and mixing by winds. The horizontal temperature gradients of SST at $10 \mathrm{~m}$ depth from both HYCOM simulations (with and without tides) reveals that the addition of tides in HYCOM results in a gradient field that is qualitatively similar to the MUR SST $\mathrm{S}_{\text {fnd }}$ gradients when compared to the simulation without tides (Fig. S4 in the online supplementary information).

The $S_{Q}=$ constant contour that lies closest to the locus of model grid points forming the boundary on the stratified side of the mixing front regions was also estimated along with the traditional Simpson Hunter parameter, $S=\log _{10}\left(\mathrm{hu}^{-3}\right)$ for the Flamborough Head, Ushant, and Islay - Malin Head fronts (Table 1). The difference between the
Table 1

Parameter values of the contour $S_{Q}=$ constant (Eq. (3)) and the SimpsonHunter parameter, $S=\log _{10}\left(\mathrm{hu}^{-3}\right)=$ constant, that lie closest to the given front location (see discussion in Sections 4 and 5 and Figs. 6-11) for HYCOM. The red numbers in brackets represent the mean distance between $S_{Q}=$ constant, $S=$ constant and the boundary of the mixing front location indicated by the potential energy anomaly (see discussion in manuscript).

\begin{tabular}{|c|c|c|}
\hline Front/location & $\mathrm{S}_{\mathrm{Q}}$ & S \\
\hline $\begin{array}{l}\text { Flamborough } \\
(\mathrm{km})\end{array}$ & $\begin{array}{l}4.8 \\
(25.0)\end{array}$ & $\begin{array}{l}2.8 \\
(25.0)\end{array}$ \\
\hline Islay - Malin Head & 5.0 & $\begin{array}{l}25.0) \\
3.2\end{array}$ \\
\hline (km) & (9.1) & (8.7) \\
\hline Ushant & 3.7 & 1.9 \\
\hline$(\mathrm{km})$ & (24.4) & $(25.7)$ \\
\hline Foxe Basin & 4.6 & 2.5 \\
\hline$(\mathrm{km})$ & (14.6) & (16.3) \\
\hline Jordan Basin & 4.1 & 1.8 \\
\hline (km) & (8.2) & $(8.6)$ \\
\hline Nantucket Shoals & 4.1 & 1.9 \\
\hline$(\mathrm{km})$ & (12.6) & (12.7) \\
\hline Georges Bank & 4.0 & 1.6 \\
\hline$(\mathrm{km})$ & (5.4) & (5.3) \\
\hline Valdez Front & 5.0 & 2.8 \\
\hline$(\mathrm{km})$ & (28.5) & (30.3) \\
\hline San Jorge Front & 4.0 & 1.9 \\
\hline$(\mathrm{km})$ & (9.1) & $(9.7)$ \\
\hline Magellan Front & 4.5 & 2.5 \\
\hline$(\mathrm{km})$ & (9.1) & (9.6) \\
\hline NWAS $119^{\circ} \mathrm{E}$ & 4.0 & 2.4 \\
\hline$(\mathrm{km})$ & (23.5) & (27.9) \\
\hline Dampier Peninsula & 4.0 & 2.1 \\
\hline$(\mathrm{km})$ & $(8.2)$ & (9.3) \\
\hline Beagle Gulf & 4.5 & 2.8 \\
\hline$(\mathrm{km})$ & (9.4) & (10.5) \\
\hline Bathurst Island & 4.5 & 2.8 \\
\hline$(\mathrm{km})$ & (6.2) & $(6.8)$ \\
\hline
\end{tabular}

parameter values of $S_{Q}$ and the traditional Simpson - Hunter parameter, $S$, is $\log _{10}(Q)=\log _{10}\left(S_{Q}\right)-\log _{10}(S)$. From Table 1 we have: $\log _{10}(Q) \sim$ $1.8-2.0$ with a mean value of $\overline{\log _{10}(Q)}=1.9$. This is equivalent to a 
seasonal average $\bar{Q}=79 \mathrm{~W} \mathrm{~m}^{-2}$; consistent with a seasonal average of $\bar{Q}=78 \mathrm{~W} \mathrm{~m}^{-2}$ over the NWES estimated from the seasonal heat flux values for JJA of Liu et al. (2015).

The HYCOM simulation with embedded tides is able to produce some tidal mixing fronts in their expected locations over the NWES. The Flamborough Head, Islay - Malin Head, and Ushant Fronts appear more or less where expected in the HYCOM simulation with tides. These fronts do not appear in the HYCOM simulation with no tides. However, HYCOM with tides does appear to over mix the coastal waters in the south east North Sea and under mix the Irish Sea.

\section{HYCOM skill in other shelf and coastal seas}

\subsection{Hudson Bay and Hudson Strait (HBS)}

Arbic et al. (2007) showed that the resonance response in the Ungava Bay and Hudson Strait is large enough to influence tides throughout the North Atlantic; Arbic et al. (2009) showed that the impact of Hudson Strait tides extends globally. Griffiths et al. (1981) previously studied the location of tidal mixing fronts in the Hudson Bay system and identified tidal mixing fronts in Foxe Basin, James Bay and Ungava Bay. The region of Hudson Bay, Hudson Strait, and the Labrador Sea dissipates $261 \mathrm{GW}$ of $\mathrm{M}_{2}$ tidal energy (Egbert and Ray, 2001); more than any other region. Based upon our estimate of $\mathrm{M}_{2}$ tidal energy dissipation, which does not include the Labrador Sea, we find that, for water column depths of 10-200 m, D $=169 \mathrm{GW}$ in TPXO8; much greater than the estimated value D $=68 \mathrm{GW}$ in HYCOM. The apparent lack of dissipation in HYCOM appears to be due to weak tidal currents within this region in the simulation used for this study.

Within the HBS region we found that for HYCOM constituent $\mathrm{M}_{2}$ the area-weighted $R M S E_{S S H}^{H B S}$ and $M E_{S S H}^{H B S}$ represent relative errors of $43-45 \%$ and $18-22 \%$ of the root mean squared amplitude $(\sim 85 \mathrm{~cm})$ for the region. HYCOM $\mathrm{M}_{2}$ amplitudes are 15-18 $\mathrm{cm}$ lower (on average) than TPXO8 and FES2014. For the $\mathrm{M}_{2}$ tidal currents, $D_{\text {ellipse }}^{\text {rel }}=67-76 \%$ with $R M S_{\text {ellipse }}^{\text {HBS }}=17.7 \mathrm{~cm} \mathrm{~s}^{-1}$. Regression analysis indicates that HYCOM and FES2014 have significantly less barotropic $\mathrm{M}_{2}$ tidal kinetic energy than in current meter observations while $\mathrm{M}_{2}$ tidal kinetic energy in TPXO8 closely matches the observed tidal kinetic energy. Details of the comparisons of the tidal heights and tidal currents for other constituents within the HBS may be found in the supplementary material accompanying the online version of this paper (Tables S5, S6 and Fig. S1).

The inclusion of tides in global HYCOM produces both positive and negative changes in model SST between $-5-5{ }^{\circ} \mathrm{C}$ (Fig. S5 in online supplementary information). The largest decreases in SST appear along the northwest coastline of Hudson Bay extending along the western and southern coastline of Southampton Island and also along the west coast of Baffin Island in Foxe Basin. The greatest increases appear in James Bay and along the east coast of Hudson Bay extending along the eastern coastline of Southampton Island and west coast of Fox Basin. Tide-induced differences in HYCOM SST values within Hudson Strait are of order $-2-2{ }^{\circ} \mathrm{C}$.

In general the inclusion of tides reduces model bias in SST in HYCOM. RMSE $E_{S S T}^{H B S}\left(T_{M U R}^{H Y C O M}\right)$ decreases by $\sim 0.4^{\circ} \mathrm{C}$ and $M E_{S S T}^{H B S}\left(T_{M U R}^{H Y C O M}\right)$ decreases in magnitude by $0.6^{\circ} \mathrm{C}$ when tides are included in the HYCOM simulation. RMSE $E_{S S T}^{H B S}\left(T_{O I S S T}^{H Y O M}\right)$ shows little change with the inclusion of tides, however, $M E_{S S T}^{H B S}\left(T_{O I S S T}^{H Y C O M}\right)$ decreases in magnitude and changes sign from $-0.5^{\circ} \mathrm{C}$ to $0.2{ }^{\circ} \mathrm{C}$, with the addition of tidal forcing (Fig. S2 in the online supplementary information). Differences in sea ice representation between HYCOM, OISST, and MUR SST fnd $_{\text {may }}$ contribute to the RMSE and ME.

The horizontal gradients of MUR SST $_{\text {fnd }}$ reveal strong temperature gradients at the mouths of James Bay and Ungava Bay and also across the channel connecting Foxe Basin with the Hudson Strait (Fig. 8). A weaker temperature gradient is also observed extending northwards into the center of Foxe Basin. The HYCOM simulation with tides produces a tidal mixing front $\left(S_{Q}=4.6\right.$; see Table 1$)$ extending north-south along the center of Foxe Basin which aligns with the weaker temperature gradient observed from the MUR $\mathrm{SST}_{\text {fnd. }}$. The location of the tidal mixing front in Foxe Basin of the HYCOM simulation is consistent with the predicted location by Griffiths et al. (1981). However, HYCOM does not indicate tidal mixing fronts across the mouths of James Bay or Ungava Bay. A comparison of the SST $(10 \mathrm{~m})$ temperature gradients between the HYCOM simulations with and without tides indicates that the Foxe Basin front results from the addition of tidal forcing and that the addition of tidal forcing increases the temperature gradients in Hudson Strait while simultaneously reducing temperature gradients in the center of Hudson Bay (Fig. S6 in the online supplementary information).

The contour of the Simpson-Hunter parameter, S, that lies closest to the tidal mixing front in Foxe Basin is $S=2.5$, indicating that $\log 10(Q)=2.1$. This is equivalent to a net downward heat flux of $125 \mathrm{Wm}^{-2}$ which is $16 \%$ greater than the mean of the net downward heat flux in the HBS, $\bar{Q}=108 \mathrm{~W} \mathrm{~m}^{-2}$, estimated from Liu et al. (2015).

\subsection{Gulf of St. Lawrence and Gulf of Maine (GSLM)}

The GSLM region contains the Bay of Fundy which is recognized as having one of the world's largest tidal ranges. Egbert and Ray (2001) estimate that tidal energy dissipation in the region of the GSLM is 60 GW. Between 10 and $200 \mathrm{~m}$ depth we find $\mathrm{D}=6.7 \mathrm{GW}$ of $\mathrm{M}_{2}$ tidal energy is dissipated due to bottom friction in TPXO8 compared to $\mathrm{D}=8.7 \mathrm{GW}$ in HYCOM within the GSLM as depicted in Fig. 1. Pingree and Griffiths (1980) studied the $\mathrm{M}_{2}$ tide in the Gulf of St. Lawrence and found that closing the Strait of Belle Isle produced near resonance conditions increasing the $\mathrm{M}_{2}$ amplitude from $25 \mathrm{~cm}$ to $160 \mathrm{~cm}$ in the Esquiman Channel.

Within the GSLM region we found that the area averaged $R M S E_{S S H}^{G L S M}$ and $M E_{S S H}^{G S L M}$ represent relative errors of $33 \%$ and 5-6\%, respectively, when compared to the root mean squared $\mathrm{M}_{2}$ amplitude $(\sim 63 \mathrm{~cm})$ estimated from TPXO8 and FES2014. Compared to tidal current velocities, model $\mathrm{M}_{2}$ barotropic currents $D_{\text {ellipse }}^{\text {rel }}=61-72 \%$ of the observed $R M S_{\text {ellipse }}^{G S L M}=24.9 \mathrm{~cm} \mathrm{~s}^{-1} \cdot \mathrm{M}_{2}$ tidal kinetic energy in HYCOM is significantly greater than the observed tidal kinetic energy while TPXO8 closely matches the observed tidal kinetic energy; FES2014 is weaker than the observed values. Details of the comparison between HYCOM, TPXO8, and FES2014 for the $\mathrm{M}_{2}$ and other tidal constituents may be found in the supplementary material accompanying the online version of this paper (Tables S5, S6 and Fig. S1).

SST differences between the HYCOM simulations (Fig. S7 in online supplementary information) indicate that SST decreases by up to $>2{ }^{\circ} \mathrm{C}$ in the mouth of the Bay of Fundy and along the south west coast of Nova Scotia due to the additional mixing induced by the action of the tides. Numerous other cold/warm core differences also appear along the track of the Gulf Stream. The tides also increase SST by $\sim 3^{\circ} \mathrm{C}$ in the St. Lawrence Seaway. Other more modest differences in SST signatures include increases (decreases) of up to $2{ }^{\circ} \mathrm{C}$ along the northern (southern) coastlines of Prince Edward Island and Cape Breton Island (Ile d'Anticosti and Newfoundland).

The inclusion of tides in HYCOM reduced model SST bias compared to the climatology by $\sim 1.0^{\circ} \mathrm{C}$. However, compared to the observed MUR SST $_{\text {fnd }}$ for JJA 2012, $R M S E_{S S T}^{G S L M}\left(T_{M U R}^{H Y C O M}\right)$ increases from $1.7^{\circ} \mathrm{C}$ to $1.9^{\circ} \mathrm{C}$ and the magnitude of $M E_{S S T}^{G S L M}\left(T_{O I S S T}^{H Y C O M}\right)$ also increases changing from $-0.5^{\circ} \mathrm{C}$ to $-1.4^{\circ} \mathrm{C}$ when tidal forcing is included. Compared to the other regional seas studied in this paper, HYCOM exhibits a large bias in SST over the GSLM (Fig. S2 in online supplementary information).

Through undertaking an analysis of mixing fronts, Pingree and Griffiths (1980) reported that Jacque Cartier Passage, which lies between Anticosti Island and the coastline of Quebec, is a region of persistent and localized cooling which they attributed to mixing by the tides. Loder and Greenberg (1986) examined the position of predicted tidal mixing fronts in the Gulf of Maine and found that tidal mixing 


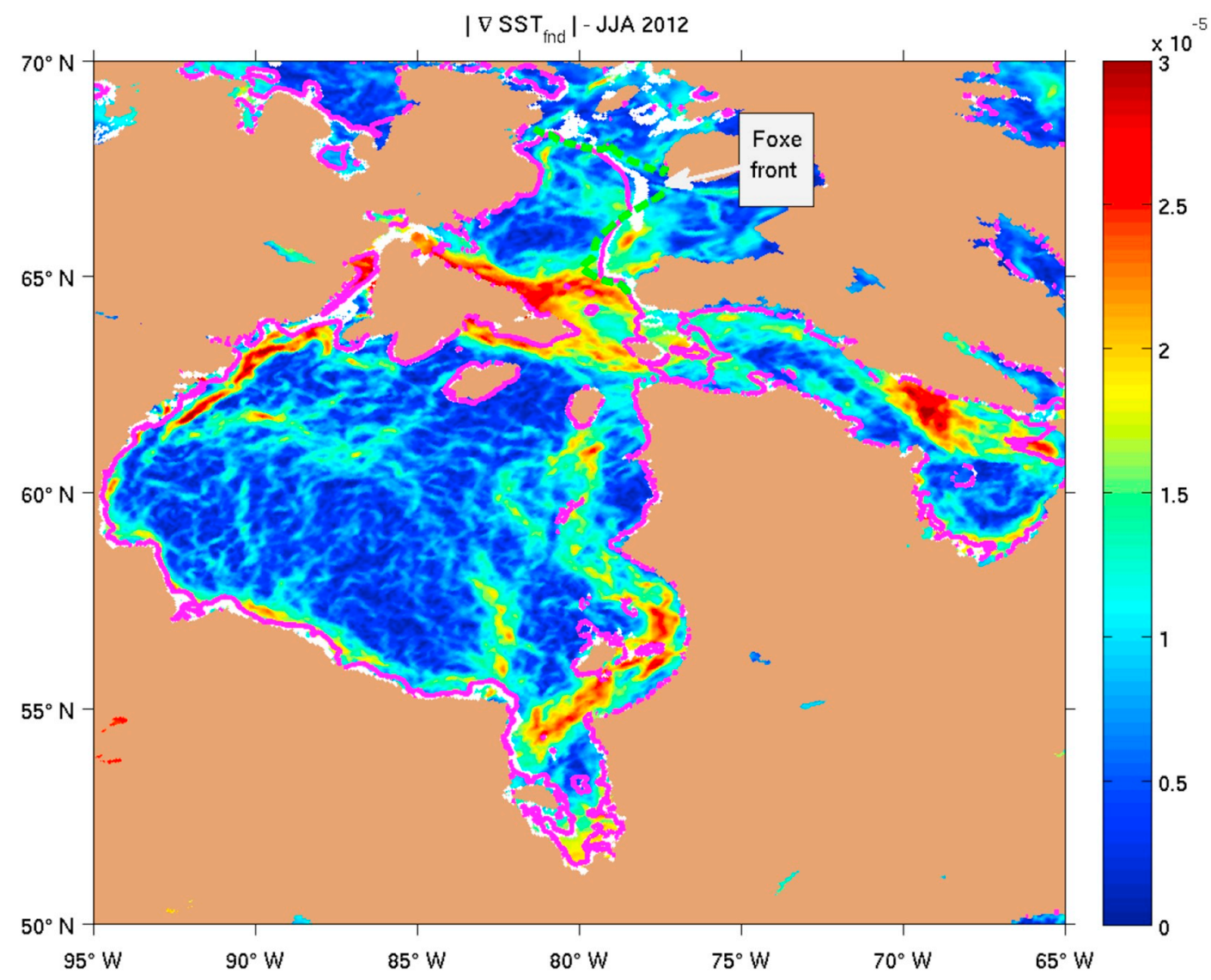

Fig. 8. Same as Fig. 7 but for Hudson Bay and Hudson Strait (HBS).

fronts may be expected off the southwest coast of Nova Scotia and also over the Nantucket Shoals and Georges Bank. In the HYCOM simulation with tides, SST in the Jacques Cartier Passage decreases by $\sim 3{ }^{\circ} \mathrm{C}$, similar to the difference observed by Pingree and Griffiths (1980). However, the passage does not become well mixed $\left(\Delta \mathrm{T} \leq 0.5^{\circ} \mathrm{C}\right)$ and does not satisfy our definition of a tidal mixing front based upon the potential energy anomaly.

Fig. 9 indicates a strong horizontal temperature gradient in MUR $\mathrm{SST}_{\text {fnd }}$ surrounding Georges Bank and weaker gradients lying off the Nantucket Shoals and in the Jordan Basin. Estimates of $S_{Q}$ based upon the HYCOM simulation with tides are listed in Table 1. The tidal mixing front in HYCOM that appears along the southwest coast of Nova Scotia

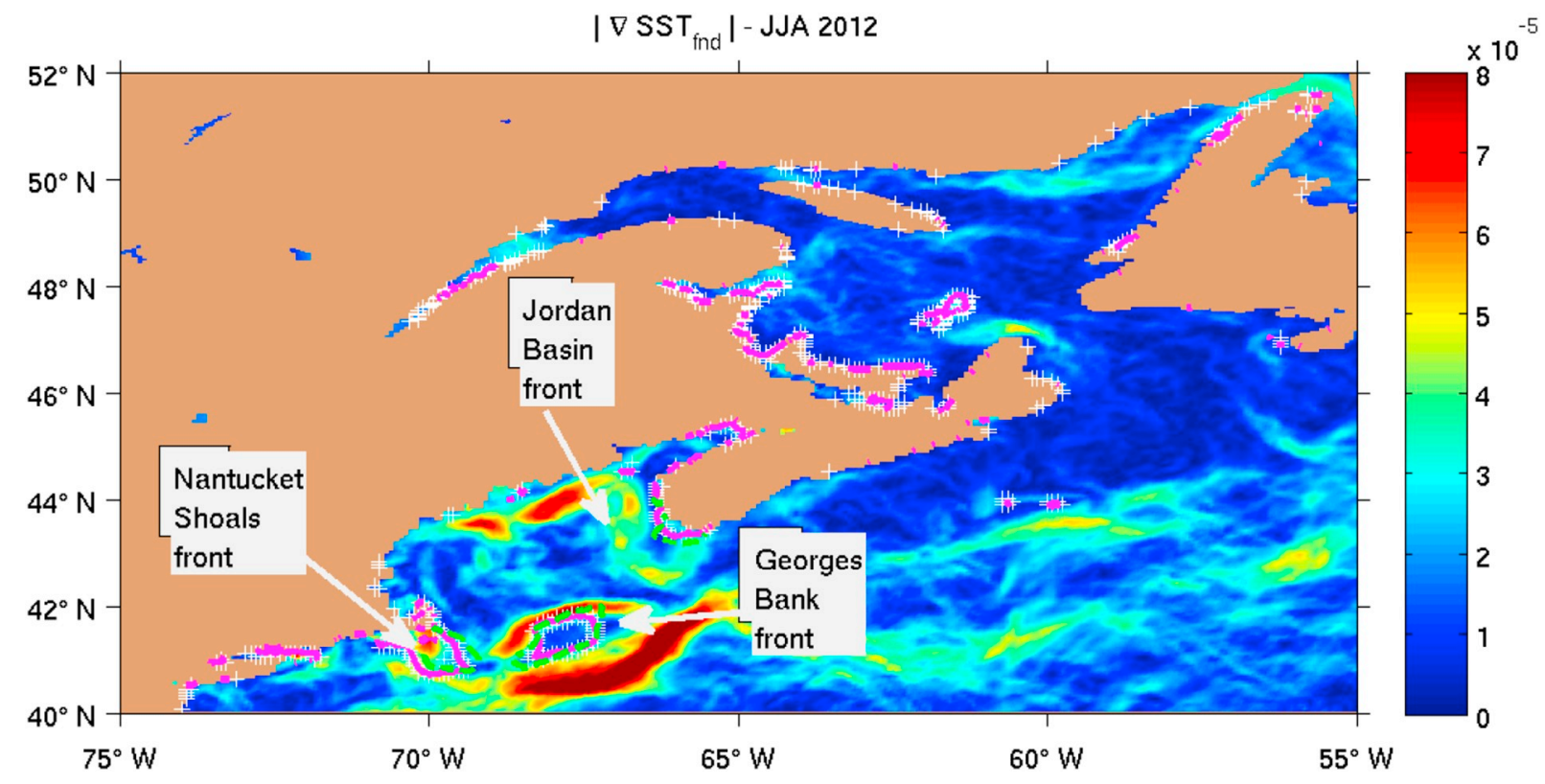

Fig. 9. Same as for Fig. 7 but for the Gulf of St. Lawrence and Gulf of Maine (GSLM). 


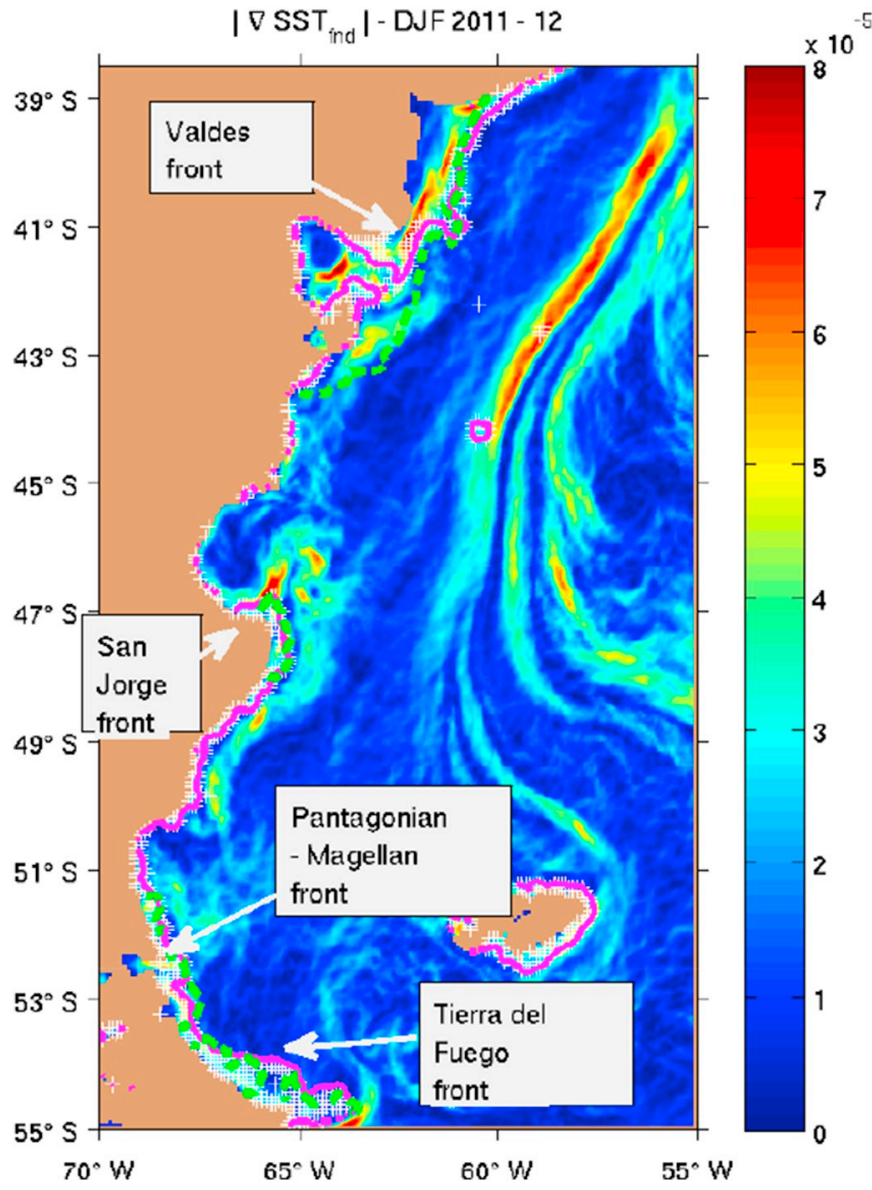

Fig. 10. Same as Fig. 7 but for the Patagonian Shelf (PS).

may be a weak formation of the Jordan Basin Front $\left(S_{Q}=4.1\right)$. Over the Nantucket Shoals $\left(S_{Q}=4.1\right)$ the tidal mixing fronts in HYCOM lie close to the strong temperature gradients in the MUR SST $\mathrm{fnd}_{\text {fnd }}$ Over George's Bank the mixing front location $\left(S_{Q}=4.0\right)$ appears entirely within the strong temperature gradient appearing in Fig. 9. One possible explanation for this may be model bathymetry which may not be truly representative of the boundary of the George's Bank region due to limited horizontal resolution. The locations of the tidal mixing fronts lying off the Nantucket Shoals and George's Bank indicated by the gradients of MUR $\mathrm{SST}_{\text {fnd }}$ are similar to the findings of Loder and Greenberg (1986) and also indicated in Belkin et al. (2009, see their Fig. 12). HYCOM does not produce the tidal mixing front in the Jacque Cartier Passage that was previously reported by Pingree and Griffiths (1980).

Horizontal temperature gradients of the $10 \mathrm{~m}$ SST field in HYCOM (Fig. S8 in online supplementary information) are consistent with those

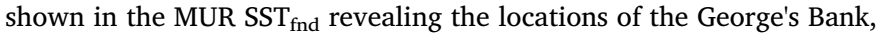
Nantucket Shoals, and Jordan Basin front. The temperature gradients in HYCOM appear to be much stronger than the temperature gradients that appear in MUR SST $\mathrm{fnd}_{\text {fnd }}$ In addition to the stronger temperature gradients over the shelf region of the Gulf of Maine and the coast of Nova Scotia, HYCOM also reveals stronger temperature gradients along the shelf break and in the Gulf of St. Lawrence.

The Simpson-Hunter parameter, $\mathrm{S}$, was also estimated from the HYCOM model output (Table 1). The mean difference between $S_{Q}$ and $S$ indicates the $\overline{\log _{10}(Q)} \sim 2.3$ which is equivalent to a net downwards heat flux of $200 \mathrm{Wm}^{-2} ; 33 \%$ greater than the mean heat flux estimated from Liu et al. (2015), $\bar{Q}=149 \mathrm{Wm}^{-2}$.

\subsection{Patagonian Shelf (PS)}

The PS is another region of large tidal range exceeding $8 \mathrm{~m}$ along the northern half of the shelf region. However, there are few in-situ observations of the tides in this region. Moreira et al. (2011) provides a recent listing of tide gauges and current meter observations for the region enclosing the northern gulfs along the PS. Of the 4 estimates of tidal ellipse parameters provided by Moreira et al. $(2009,2011)$ only one was located in a region where the water column depth was $>10 \mathrm{~m}$. For this single observation we find that the RMS difference (Eq. (8b)) is $D_{u}($ model $)=10.7,10.5$, and $5.2 \mathrm{~cm} \mathrm{~s}^{-1}$ for models: HYCOM, TPXO8, and FES2014, respectively.

Egbert and Ray (2001) estimated that 108-112 GW of tidal energy is dissipated in this region. An early numerical modelling study by Glorioso and Simpson (1994) provided an estimate of $\sim 90$ GW of dissipation. Between 10 and $200 \mathrm{~m}$ water column depth we find that $\mathrm{D}=122 \mathrm{GW}(105 \mathrm{GW})$ in TPXO8 (HYCOM). $R M S E_{S S H}^{P S}$ and $M E_{S S H}^{P S}$ represent relative errors of $20 \%$ and $2 \%$, respectively of the root mean squared amplitude $(\sim 88 \mathrm{~cm})$. For HYCOM and TPXO8, $D_{\text {ellipse }}^{\text {rel }}=52-53 \%$ and for FES2014, $D_{\text {ellipse }}^{\text {rel }}=26 \%$ compared to the single observation for the M2 tidal current $\left(R M S_{\text {ellipse }}^{P S}=20.1 \mathrm{~cm} \mathrm{~s}^{-1}\right)$. Details of the comparison between HYCOM, TPXO8, and FES2014 may be found in the supplementary material accompanying the online version of this paper (Tables S5, S6 and Fig. S1).

Differences in HYCOM SST when tides are included range between $-2-2{ }^{\circ} \mathrm{C}$ with the largest changes occurring along the north west coast of the PS between 39 and $43^{\circ} \mathrm{S}$ (Fig. S9 in online supplementary information). HYCOM SST bias decreases by $\sim 0.3^{\circ} \mathrm{C}$ compared to the climatology when tides are included in the simulation. However for DJF 2011-2012 $\mathrm{ME}_{S S T}^{P S}\left(T_{M U R}^{H Y C O M}\right)$ increases by $0.3^{\circ} \mathrm{C}$ compared to satellite observations (MUR SST ${ }_{\text {fnd }}$ ) for that period when tides are included (Fig. $\mathrm{S} 2$ in online supplementary information).

Glorioso (1987) observed strong horizontal temperature gradients and intensified mixing near the Peninsula of Valdez $\left(42^{\circ}-43^{\circ} \mathrm{S}\right)$. Glorioso and Simpson (1994) used a numerical model to examine the location of tidal mixing fronts and estimated that the observed front corresponded to a critical value of the Hunter - Simpson parameter, $\mathrm{S}=2.3 \pm 0.2$. Glorioso and Flather (1995) also modelled the tides on the Patagonian Shelf and found that tidal mixing fronts may also be expected at both ends of Golfo San Jorge $\left(\sim 46^{\circ} \mathrm{S}\right)$, and Bahia Grande $\left(\sim 51^{\circ} \mathrm{S}\right)$.

MUR SST $T_{\text {fnd }}$ reveals strong temperature gradients indicating the location of the Valdez and San Jorge Fronts (Fig. 10). HYCOM also produces tidal mixing fronts along the coastline between $39^{\circ}-43^{\circ} \mathrm{S}$ and $47^{\circ}-49^{\circ} \mathrm{S}$ corresponding to the Valdez $\left(S_{Q}=5.0\right)$ and San Jorge Front $\left(S_{Q}=4.0\right)$ that lie close to the MUR $S_{S T} T_{\text {fnd }}$ temperature gradients. The Patagonian-Magellan Front, and Tierra del Fuego Front also appear in both the MUR $\operatorname{SST}_{\text {fnd }}$ and HYCOM simulation $\left(S_{Q}=4.5\right)$. Belkin et al. (2009) attributes the Magellan Front to the influx of cold, fresh water via the Strait of Magellan and around the southern tip of Tierra del Fuego. However, our results indicate that tides appear to play a role as the well-mixed water remains trapped closer to the coastline, as indicated by the location of the HYCOM $10 \mathrm{~m}$ temperature gradient, between $51^{\circ}-55^{\circ} \mathrm{S}$ in the HYCOM simulation with no tides (Fig. S10 in online supplementary information).

The mean difference between $S_{Q}$ and the Simpson-Hunter parameter, $S$, (Table 1) indicates that on the PS $\overline{\log _{10}(Q)}=2.1$ which suggests an average downwards heat flux of $Q=126 \mathrm{Wm}^{-2}$, comparable to the average value $\bar{Q}=127 \mathrm{Wm}^{-2}$ estimated from Liu et al. (2015).

\subsection{Northwest Australian Shelf (NWAS)}

Holloway (1983) conducted one of the first studies of the tides on the NWAS which has a tidal range exceeding $6 \mathrm{~m}$ and $\mathrm{M}_{2}$ tidal currents decreasing from $28 \mathrm{~cm} \mathrm{~s}^{-1}$ to $16 \mathrm{~cm} \mathrm{~s}^{-1}$ over a distance of only $20 \mathrm{~km}$. In a later modelling study, Holloway (2001) estimated an average 
dissipation rate of $0.011 \mathrm{Wm}^{-2}$ and vertical eddy viscosity of $10^{-4} \mathrm{~m}^{2} \mathrm{~s}^{-1}$. The high vertical mixing rates may be expected to contribute to the downwards mixing of incoming solar radiation and hence the possible formation of tidal mixing fronts.

Egbert and Ray (2001) estimate that 158-179 GW of $\mathrm{M}_{2}$ tidal energy is dissipated on the NWAS. Between 10 and $200 \mathrm{~m}$ depth we find that the $\mathrm{M}_{2}$ tidal energy dissipation $D=122 \mathrm{GW}$ in TPXO8 and $107 \mathrm{GW}$ in HYCOM. $R M S E_{S S H}^{N W A S}$ and $M E_{S S H}^{N W A S}$ represent relative errors of $29-30 \%$ and $14-15 \%$, respectively, of the root mean squared tidal amplitude $(\sim 90 \mathrm{~cm})$ for the NWAS. For the $\mathrm{M}_{2}$ barotropic tidal currents $D_{\text {ellipse }}^{\text {rel }}=35-41 \%$ in HYCOM and FES2014 and $D_{\text {ellipse }}^{\text {rel }}=66 \%$ in TPXO8; $R M S_{\text {ellipse }}^{N W A S}=18.6 \mathrm{~cm} \mathrm{~s}^{-1}$. Details of the comparison of tidal amplitudes between HYCOM, TPXO8, and FES2014 may be found in the supplementary material accompanying the online version of this paper (Tables S5, S6 and Fig. S1 in online supplementary information).

Differences in SST for HYCOM simulations with and without tides range between $-2-0.5^{\circ} \mathrm{C}$ with the largest cooling occurring between 120 and $126^{\circ} \mathrm{W}$ and $12-18^{\circ} \mathrm{S}$ (Fig. S11 in online supplementary information). The inclusion of tides reduces model bias in SST compared to the climatology but increases SST bias compared to observations in DJF 2011-2012. RMSE $E_{S S T}^{N W A S}\left(T_{O I S S T}^{H Y C M}\right)$ and $M E_{S S T}^{N W A S}\left(T_{O I S S T}^{H Y C M}\right)$ decreased by $0.4-0.5{ }^{\circ} \mathrm{C}$ when tides were included in the HYCOM simulation. $\operatorname{RMSE}_{S S T}^{N W A S}\left(T_{M U R}^{H Y C O M}\right)$ increased by $0.3^{\circ} \mathrm{C}$ and $M E_{S S T}^{N W A S}\left(T_{M U R}^{H Y C O M}\right)$ increased and changed sign from $<0.01{ }^{\circ} \mathrm{C}$ to $-0.5^{\circ} \mathrm{C}$ when tides were included (Fig. S2 in the online supplementary information).
The horizontal temperature gradients of MUR $\operatorname{SST}_{\text {fnd }}$ (Fig. 11) indicate a strong gradient lying near the coast from 114 to $122^{\circ} \mathrm{E}$. There are also weaker gradients north of the Dampier Peninsula (122-123 E, $\left.15-17^{\circ} \mathrm{S}\right)$ and across the western mouth of Beagle Gulf (129-130 E, $\left.12-13^{\circ} \mathrm{S}\right)$, and over the banks west of Melville and Bathurst islands $\left(128-131^{\circ} \mathrm{E}, 11-12^{\circ} \mathrm{S}\right)$. The insets on Fig. 11 show the regions in which we have chosen to study the impact of tidal forcing on frontal positions on the NWAS. Mixing front locations based upon the potential energy anomaly for the simulation with tides (without) are shown as white ' + ' (white 'o') thatching.

Daily mean temperatures estimated from observations from the Australian National Mooring Network (ANMN) Facility (IMOS, 2018) between July 2011 and July 2017 show the collapse of the stratification on the NWAS during the Austral winter (JJA) and reforms during the Austral spring and summer (Fig. 12). The location of the 4 mooring sites: ITFMHB, ITFFTB, KIM200, and PIL100, are shown as red squares in Fig. 11. Vertical cross sections, from the HYCOM simulations with and without tides, of the potential density field along the gray lines in Fig. 12 are shown in Fig. 13.

Along $119^{\circ} \mathrm{E}$ both of the simulations with and without tides indicate a region of well mixed water extending from the coastline (Fig. 11). This frontal region lying over the $40 \mathrm{~m}$ bathymetric contour has been discussed previously by Tranter and Leech (1987). However they discounted the role of tides due to the high solar irradiation $\left(>200 \mathrm{Wm}^{-2}\right)$. Condie and Andrewartha (2008) attributed the

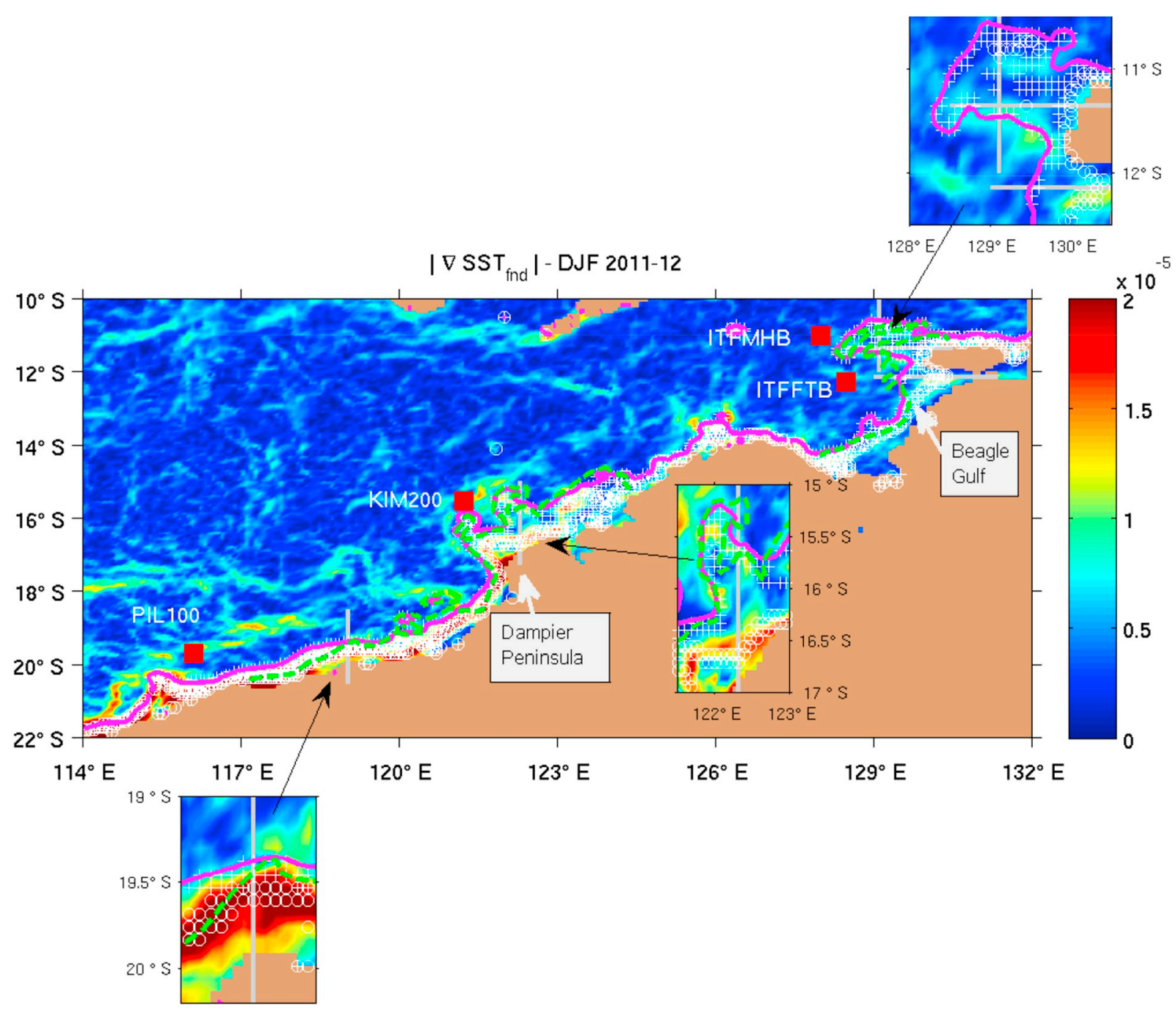

Fig. 11. Temperature profiles from IMOS (2018) sites show the annual collapse of the stratification over the Northwest Australian Shelf (NWAS) during the Austral winter. The site locations are indicated in Fig. 11 as red squares. 


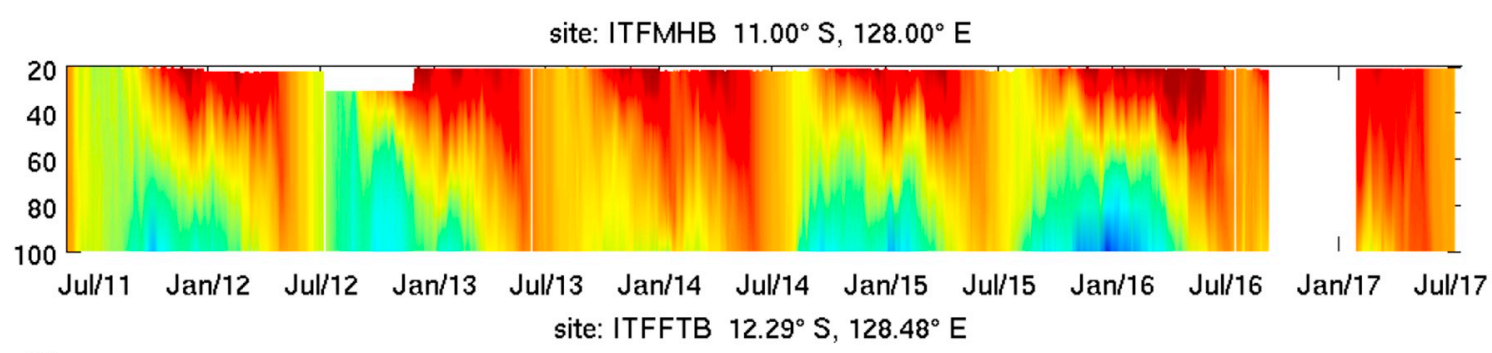

${ }^{\circ} \mathrm{C}$
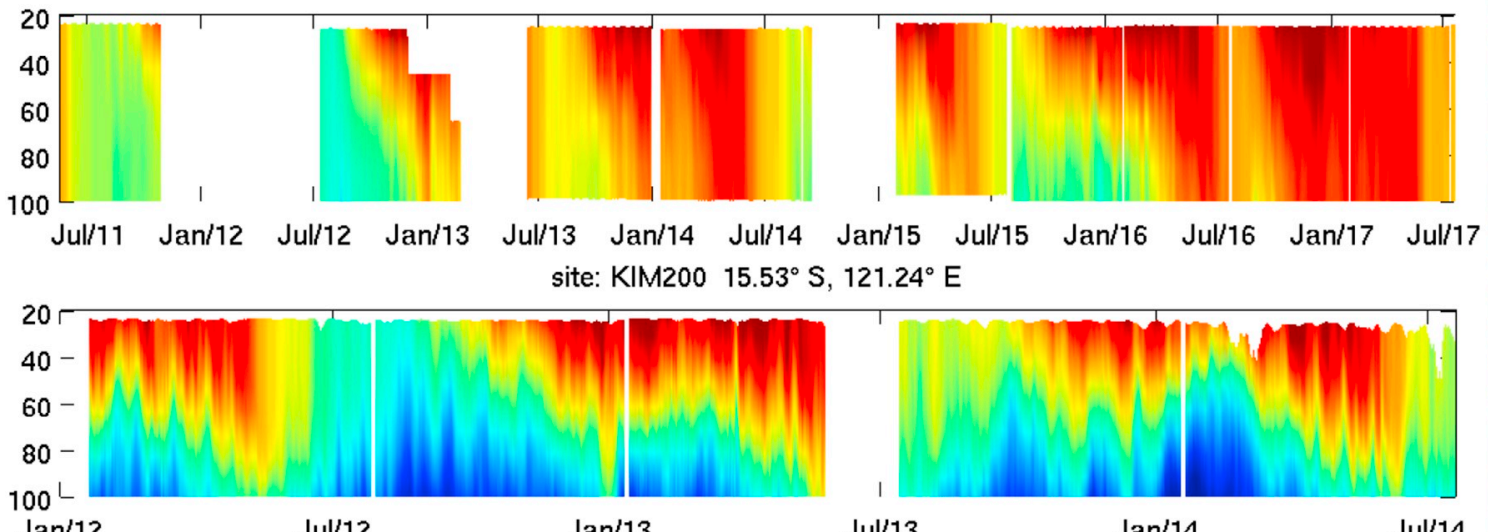

$\underset{\operatorname{Jan} / 12}{100^{-}}$

$\mathrm{Jul} / 12$

Jan/13

\begin{abstract}
$\mathrm{Jul} / 13$
\end{abstract}

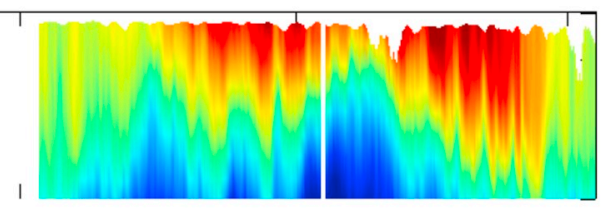

site: PIL100 $19.69^{\circ} \mathrm{S}, 116.11^{\circ} \mathrm{E}$
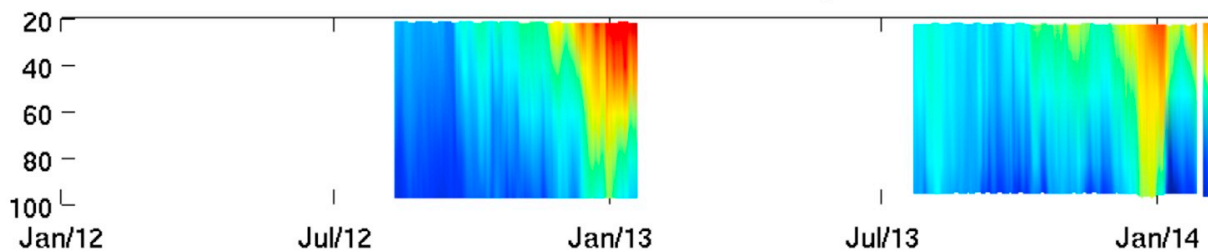

Jan/14

Jul/14

Jul/14

Fig. 12. Horizontal temperature gradient for MUR $\mathrm{SST}_{\text {fnd }}$ (Chin et al., 2017). The locations of tidal mixing fronts in HYCOM (satisfying $|\nabla \phi|>2.5 \cdot 10^{-4}$ and $\phi<10 \mathrm{~J} \mathrm{~m}^{-3}$ ) are indicated by white '+' producing thatched regions. The mixing front locations in the HYCOM simulation without tides are indicated by white ' $\mathrm{o}$ '. The magenta line indicates the location of the $\Delta \mathrm{T}=0.5^{\circ} \mathrm{C}\left(\mathrm{SST}-\mathrm{SBT}\right.$ ) contour in HYCOM. The dashed green line indicates of the contour $\mathrm{S}_{\mathrm{Q}}=$ constant that has minimum mean distance to the mixing front location (see Table 1 for the values of $\mathrm{S}_{\mathrm{Q}}$ ). The red squares indicated the location of the IMOS (2018) temperature profiles shown in Fig. 12. The inset panels provide a higher resolution view of the mixing front locations discussed in the manuscript.

location of the front between the well mixed water near the coast and around the Dampier Peninsula to the vertical mixing to due to the high shear induced by tidal motions. They observed that well mixed water extended to the $50 \mathrm{~m}$ bathymetric contour during spring tides and the $30 \mathrm{~m}$ bathymetric contour during neap tides. However they did not provide estimates of the front location in terms of the Simpson - Hunter parameter. Over the NWAS the net downward heat flux (Liu et al., 2015), $\bar{Q}=62 \mathrm{Wm}^{-2}$, is much smaller than the solar irradiation of $>$ $200 \mathrm{Wm}^{-2}$ stated by Tranter and Leech. We find that the addition of tides in HYCOM shifts the front location (indicated by the magenta diamonds at the top of the individual panels in Fig. 13) approximately $25 \mathrm{~km}$ further offshore; lying above the 40 bathymetric contour instead of the $30 \mathrm{~m}$ bathymetric contour in the simulation without tides, close to matching the fronts in the study of Condie and Andrewartha (2008). Based upon the HYCOM simulation with tides we estimate that in this region the Simpson - Hunter parameter is $S=2.4$ and $S_{Q}=4.0$ which is consistent with other tidal mixing fronts.

North of the Dampier Peninsula tidal mixing fronts $\left(S_{Q}=4.0\right)$ appear over the shallow banks; these mixing fronts do not appear in the HYCOM simulation with no tides although a front does appear much closer to the coastline (Fig. 11). Along the transect at $\left(122.32^{\circ} \mathrm{E}\right)$ the mixing front that lies north of the Dampier Peninsula shifts $\sim 111 \mathrm{~km}$ northwards lying over the $50 \mathrm{~m}$ bathymetric contour instead of the $30 \mathrm{~m}$ bathymetric contour when tidal forcing is not included in the HYCOM simulation (Fig. 13). A similar situation occurs across the western boundary of the Beagle Gulf. With the addition of tidal forcing in HYCOM the front location along the transect lying east-west along $12.148^{\circ} \mathrm{S}$ indicates that the mixing front across the mouth of Beagle Gulf $\left(\mathrm{S}_{\mathrm{Q}}=4.5\right)$ shifts westwards approximately $90 \mathrm{~km}$ from $130.3^{\circ} \mathrm{E}$ to $129.5^{\circ} \mathrm{E}$ once again lying over the $50 \mathrm{~m}$ bathymetric contour instead of the $30 \mathrm{~m}$ bathymetric contour in the non-tidal simulation.

The shallow banks lying west of Melville and Bathurst Islands $\left(128-131^{\circ} \mathrm{E}, 11-12^{\circ} \mathrm{S}\right)$ are another region where we find evidence of tidal mixing fronts. These fronts do not appear in the HYCOM simulation with no tides (Fig. S12 in online supplementary information). The two transects lying east-west $\left(11.365^{\circ} \mathrm{S}\right)$ and north-south $\left(129.12^{\circ} \mathrm{E}\right)$ show that tidal mixing fronts $\left(\mathrm{S}_{\mathrm{Q}}=4.5\right)$ form over the banks. In the HYCOM simulation without tides the mixing front is restricted to the very shallowest region over the bank.

HYCOM produces mixing fronts that align with the gradients observed in the MUR SST ${ }_{\text {fnd }}$ although the temperature gradients of the SST at $10 \mathrm{~m}$ depth in HYCOM are much stronger temperature gradients than observed in the MUR SST fnd (Fig. S12). Differences between $S_{Q}$ and $S$ (Table 1) for the four fronts located on the NWAS indicate that $\overline{\log 10(Q)}=1.73$ which is equivalent to $53 \mathrm{~W} \mathrm{~m}^{-2}$ for the net downward heat flux, close to the estimates from Liu et al. (2015), $\bar{Q}=62 \mathrm{~W} \mathrm{~m}^{-2}$.

\section{Discussion and conclusions}

We have compared two HYCOM simulations, with and without embedded tides, to assess the impact of adding tides on shelf sea mixing in a global 3-dimensional ocean general circulation model. The global HYCOM ASEnKF experiment with tides is forced by 5 tidal constituents 

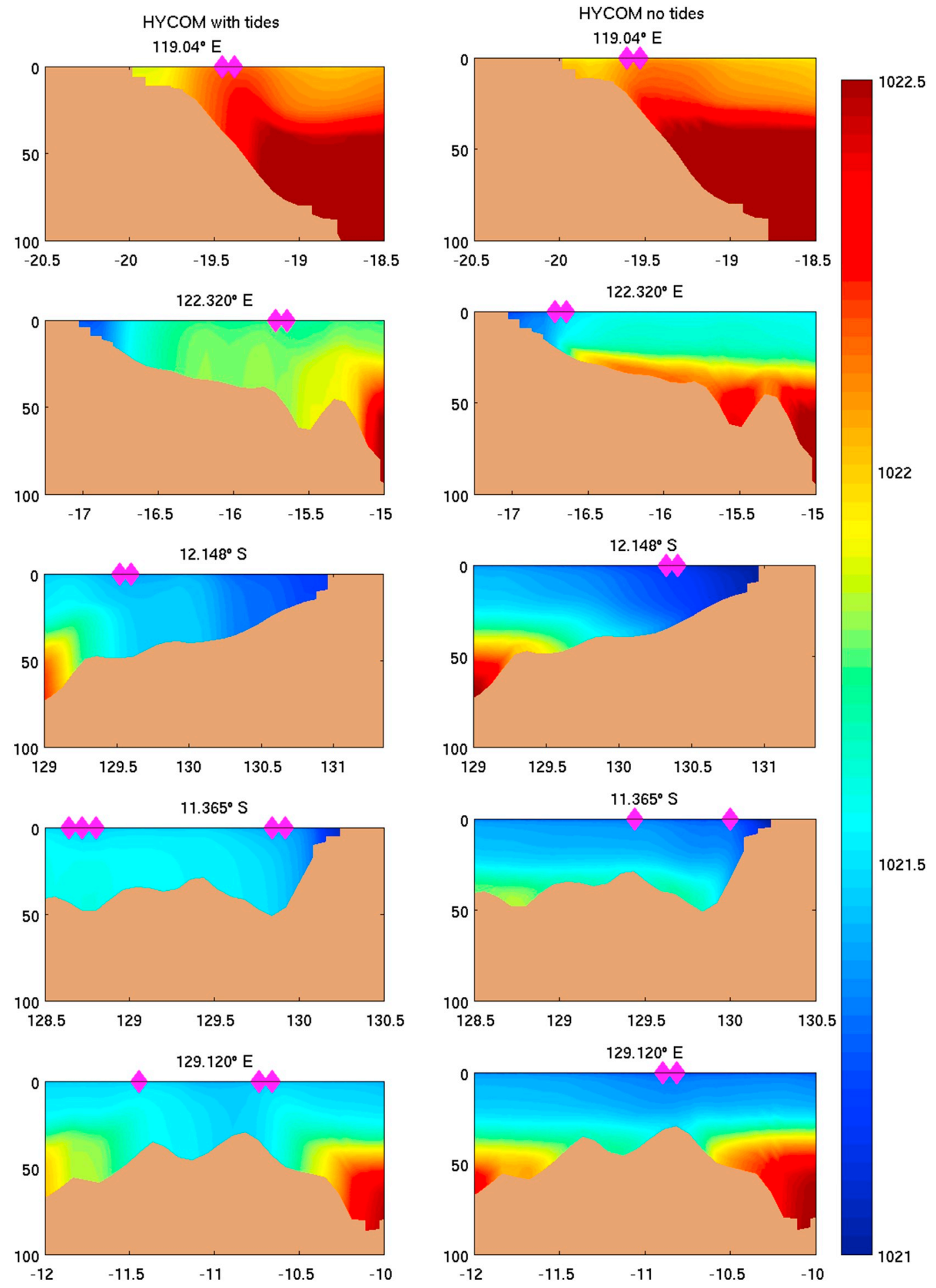

Fig. 13. Vertical profiles of the potential density along transects over the Northwest Australian Shelf (NWAS) from the HYCOM simulations with (left column) and without (right column) tides. Transect locations are shown as gray lines in Fig. 11 and highlighted as panel insets. The magenta diamonds along the top of each panel indicate the mixing front locations in HYCOM (satisfying $|\nabla \phi|>2.5 \cdot 10^{-4}$ and $\phi<10 \mathrm{~J} \mathrm{~m}^{-3}$ ).

$\left(\mathrm{M}_{2}, \mathrm{~S}_{2}, \mathrm{~N}_{2}, \mathrm{~K}_{1}\right.$, and $\left.\mathrm{O}_{1}\right)$ and includes an improved bathymetry under the ice shelves in Antarctica but otherwise the grid and model forcing for HYCOM simulations with and without tides are identical.

Our comparison indicates that the addition of tides to the global simulations produces a visible difference in shelf SST signatures on a seasonal basis. In this HYCOM experiment we find that the addition of tidal forcing reduces the global RMSE and ME between HYCOM and OISST. Compared to MUR SSTfnd concurrent with the HYCOM simulations, however, the inclusion of tides increases the error during JJA. As the HYCOM simulations presented here are non-assimilative, the RMSE $E_{S S T}$ and MESST may be dominated by model biases. Globally, $\mathrm{RMSE}_{\mathrm{SST}}$ is of order $0.7-1.5^{\circ} \mathrm{C}$ and $\mathrm{ME}_{\mathrm{SST}}$ of order $\pm 0.4^{\circ} \mathrm{C}$.

Compared to the shallow water tide gauges used by Stammer et al. (2014) the global HYCOM simulation used in this study has a RMSE of $24.1 \mathrm{~cm}$ for $\mathrm{M}_{2}$ which is large compared to the RMSE of $3.6 \mathrm{~cm}$ and $3.7 \mathrm{~cm}$ for TPXO8 and FES2014, respectively. RMSE for constituent $\mathrm{S}_{2}$ 
in HYCOM is $10.9 \mathrm{~cm}$ (5-6 times larger than the TPXO8 and FES2014) errors. The other tidal constituents $\left(\mathrm{N}_{2}, \mathrm{~K}_{1}\right.$, and $\left.\mathrm{O}_{1}\right)$ in HYCOM have RMSE $<6 \mathrm{~cm}$ and are up to 2-4 times larger than the RMSE for TPXO8 and FES2014. Over the global coastal and shelf seas the area-averaged RMSE between HYCOM and TPXO8/FES2014 indicates that HYCOM has a relative error of $35 \%$ compared to the root mean squared amplitude of $50 \mathrm{~cm}$. The large relative error appears to indicate a problem with tidal phase in the coastal and shelf seas and is most likely due to oversimplified parameterizations of bottom friction, and inadequate coastal geometry. On the NWES, RMSE for global HYCOM is also twice as large as the non-assimilative NEMO simulation of O'Dea et al. (2012).

The tidal kinetic energy in HYCOM, TPXO8, and FES2014 are similar to the tidal kinetic energy estimated from in-situ current meter observations. Global $\mathrm{M}_{2}$ tidal energy dissipation for shelf and coastal seas between 10 and $200 \mathrm{~m}$ depth in this study appears weaker in HYCOM (881 GW) compared to estimates from TPXO (1313 GW). However, in another study Buijsman et al. (2015), using a different HYCOM experiment, reported that global HYCOM produced reasonable dissipation estimates compared to TPXO.

In the regional seas examined in more detail in this paper we find that the RMSE and ME in $\mathrm{M}_{2}$ represent from 20 to $45 \%$ of the root mean squared signal when HYCOM is compared to the satellite constrained models TPXO8 and FES2014. Barotropic $\mathrm{M}_{2}$ tidal kinetic energy in HYCOM is greater than both TPXO8 and FES2014 over the NWES, GSLM, and NWAS. In the HBS HYCOM barotropic $\mathrm{M}_{2}$ tidal kinetic energy is less than observed.

In this paper we examined the ability of global HYCOM with embedded tides to reproduce tidal mixing fronts within selected shelf seas. Overall HYCOM exhibits reasonable skill in producing known tidal mixing fronts in the shelf seas, and the locations of these mixing fronts are consistent with predicted locations based upon the Simpson-Hunter parameter and comparable to horizontal gradients in MUR SST $\mathrm{fnd}_{\text {fnd }}$ We have chosen to use a modified form of the Simpson-Hunter parameter, in which we have included the heat flux in order to compare tidal mixing front locations on a global scale. Based upon the 14 tidal mixing fronts examined in the HYCOM with tides simulation we find that the mixing front locations generally occur along contours of $S_{Q}=4.3 \pm 0.4$. Our analysis of the same fronts using the Simpson-

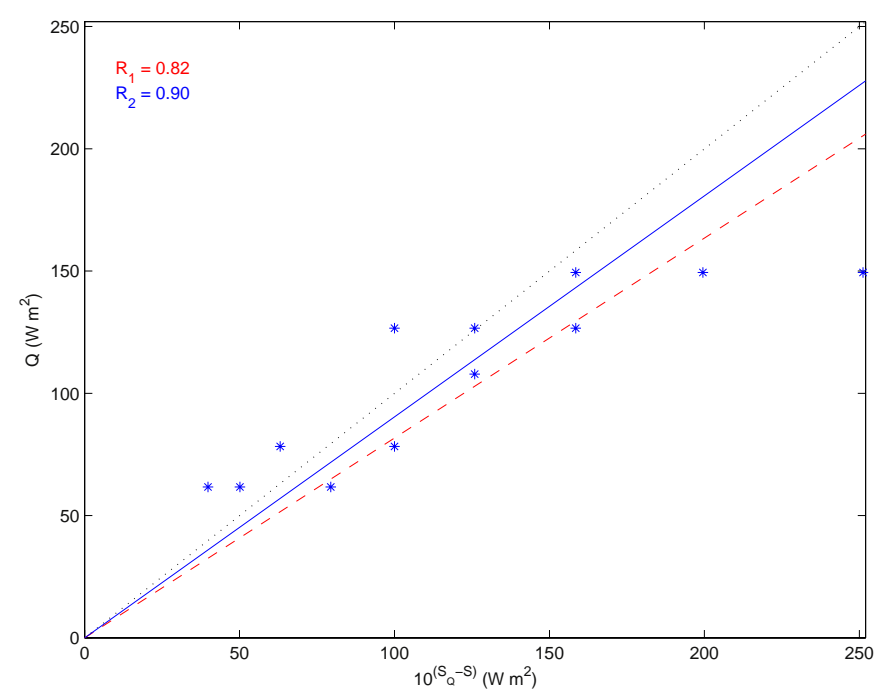

Fig. 14. Downward heat flux, $Q$, vs. inferred heat flux $10_{\mathrm{Q}}^{(\mathrm{S}-\mathrm{s})}$. Downward heat flux, $Q$, is the average value of the heat flux estimated from satellite data (Liu et al., 2015) for each of the regions shown in Fig. 1. Inferred heat flux is estimated from the difference between the values of $S_{Q}$ and $S$, i.e. Inferred Heat Flux $=10_{\mathrm{Q}}^{(\mathrm{S}-\mathrm{s})}$. The red dashed line represents the regression coefficient using all 14 data points $\left(R_{1}=0.82\right)$. The blue line represents the regression coefficient estimated by excluding the parameter values for George's Bank $\left(\mathrm{R}_{2}=0.90\right)$. The black dotted line represents $R=1$.
Hunter parameter, $S$, indicates that the fronts occur along the contour of $S=2.4 \pm 0.5$.

Regression analysis (Fig. 14) between the average heat flux, estimated from satellites (Liu et al., 2015), for each region vs. the inferred value of the heat flux based upon the difference between the contour value of $S_{Q}$ and $S$ lying closest to the individual tidal mixing fronts indicates that the regression coefficient is $R=0.82$. The difference in the downwards heat flux estimated from $\mathrm{S}_{\mathrm{Q}}$ and $\mathrm{S}$ over Georges Bank in the GSLM is large compared to other values. This value appears to exhibit significant leverage when estimating the regression coefficient. When the value from the Georges Bank is excluded from the analysis the regression coefficient increases to $R=0.90$.

The existence and location of the mixing fronts serves as a proxy to estimate the amount of vertical mixing that occurs within the individual shelf seas. In the North Sea HYCOM may be over-energetic resulting in a merging of several known frontal locations, while at the same time appearing to be under-energetic in the Irish Sea resulting in a stratified Irish Sea and no manifestation of the Western Irish Sea or Celtic Fronts. The Islay - Malin Head Front extending across the western side of Northern Passage is in its expected location.

HYCOM also predicts the existence of a tidal mixing front extending through Foxe Basin. However, the existence of this particular front is uncertain due to the influence of sea-ice. Within the Gulf of St. Lawrence, the addition of tides in HYCOM appears to enhance mixing between Prince Edward Island and the mainland, but does not produce enough vertical mixing to yield a known mixing front in the Jacque Cartier Passage. In the Gulf of Maine, HYCOM reproduces known tidal mixing fronts over the Nantucket Shoals and Georges Bank. On the Patagonian Shelf, HYCOM is able to reproduce the Valdez and San Jorge Fronts and enhance mixing to displace the Magellan Front further from the coastline.

In the past there has been some doubt as to whether the mixing front on the NWAS between 114 and $122^{\circ} \mathrm{E}$ is due to the tides since the solar irradiation is high in the lower latitudes (Tranter and Leech, 1987). However our study, based upon the net downward heat flux, indicates that the tides do have a small but measureable impact on the location of the front in this region. We have been unable to identify previous mention within the scientific literature of the tidal mixing fronts north of the Dampier Peninsula and west of Beagle Gulf and Melville and Bathurst islands and have provided estimates of the Simpson - Hunter parameter for the fronts we identified in these regions. If scientific studies identifying the tidal mixing fronts within these regions have been conducted in the past they are not known to us.

It is evident from the above discussion that HYCOM with embedded tides does have significant skill in reproducing tidal mixing fronts within shelf seas even though the model may have less skill than highly accurate data-assimilative barotropic tide models in reproducing observed tidal heights and tidal currents. It is also clear that model performance varies significantly over the different shelf seas. Considering that HYCOM was tuned to minimize the RMSE in $\mathrm{M}_{2}$ tidal heights in deep water, we believe that global HYCOM displays reasonable skill in representing the shelf sea tides. However, because the shelf seas have such a prominent role in the dissipation of tidal energy, minimizing the RMSE and ME within the shelf seas, and improving the integrated dissipation of tidal energy in these regions, potentially has significant implications for the global tide solution. If too little or too much tidal energy is being dissipated in the shelf seas then the amount of tidal kinetic energy available for dissipation in the deep ocean will also be too large or too small. This has implications for estimates of mixing within the deep ocean.

The Navy global HYCOM prediction system is undergoing continuous development. The tides are sensitive to bathymetry and damping, for instance, and these are continually being updated in HYCOM. The ASEnKF is currently being updated to account for regions of strong coastal tides, which were not accounted for in the perturbations used in Ngodock et al. (2016). We are also experimenting with 
two-way nesting in regional of strong coastal tides. These improvements are likely, over time, to continue the trend seen over the past decade, in which HYCOM tidal errors have continually gone down. The process is slow, however, and in the meantime regional models are still likely to be more accurate for specific applications. Higher resolutions may help improve HYCOM's ability to resolve tidal mixing fronts by providing better representation of bathymetry and coastal features. Here we have shown that global models at existing resolutions of $1 /$ $12.5^{\circ}$ are able to exhibit some degree of skill in replicating shelf tides and tidal mixing fronts.

\section{Acknowledgements}

The authors would like to thank Prof. John Simpson of Bangor University in Wales, three anonymous reviewers, and the editors of Ocean Modelling for providing many useful comments and suggestions on earlier drafts of this manuscript. We would also like to thank Jeff Book, Naval Research Laboratory, for providing insight and advice on the study of the North West Australian Shelf. Most of BKA's contributions to this paper took place while he was on sabbatical in France. BKA thanks many French colleagues, especially Thierry Penduff, Rosemary Morrow, and Nadia Ayoub, for their help in procuring this sabbatical year. Data was sourced from the Integrated Marine Observing System (IMOS) - an initiative of the Australian Government being conducted as part of the National Collaborative Research Infrastructure Strategy and the Super Science Initiative. Data and code used to reproduce the figures and tables in this manuscript is available upon request from the corresponding author. BKA acknowledges support from the Office of Naval Research (grant N00014-15-1-2288). PH acknowledges support from the Joint UK BEIS/Defra Met Office Hadley Centre Climate Programme (GA01101). The statements, findings, conclusions, and recommendations are solely the opinions of the authors and do not constitute a statement of policy, decision, or position on behalf of The Royal Meteorological Society nor the Welsh Local Centre. This is NRL contribution NRL/JA/7320-17-3442 and has been approved for public release.

\section{Appendix A. Supplementary data}

Supplementary data to this article can be found online at https:// doi.org/10.1016/j.ocemod.2019.02.008.

\section{References}

Acha, E.M., Mianzan, H.W., Guerro, R.A., Favero, M., Bava, J., 2004. Marine fronts at the continental shelf of austral South America: physical and ecological processes. J. Mar. Syst. 44, 83-105.

Ansong, J.K., Arbic, B.K., Buijsman, M.C., Richman, J.G., Shriver, J.F., Wallcraft, A.J., 2015. Indirect evidence for substantial damping of low-mode internal tides in the open ocean. J. Geophys. Res. Oceans 120, 6057-6071. https://doi.org/10.1002/ 2015JC010998.

Ansong, J.K., Arbic, B.K., Alford, M.H., Buijsman, M.C., Shriver, J.F., Zhao, Z., Richman, J.G., Simmons, H.L., Timko, P.G., Wallcraft, A.J., Zamudio, L., 2017. Semidiurnal internal tide energy fluxes and their variability in a global ocean tide model and moored observations. J. Geophys. Res. Oceans 122, 1882-1900. https://doi.org/10. 1002/2016JC012184.

Arbic, B.K., Garner, S.T., Hallberg, R.W., Simmons, H.L., 2004. The accuracy of surface elevations in forward global barotropic and baroclinic tide models, Deep Sea Res. II 51, 3069-3101.

Arbic, B.K., St. Laurent, P., Sutherland, G., Garrett, C., 2007, On the resonance and influence of tides in Ungava Bay and Hudson Strait, Geophys. Res. Lett. 34, L17606, doi:10.10129/2007GL030845.

Arbic, B.K., Karsten, R.H., Garrett, C., 2009. On tidal resonance in the global ocean and the back-effect of coastal tides upon open-ocean tides. Atmos.-Ocean 47, 239-266. https://doi.org/10.3137/OC311.2009.

Arbic, B.K., Wallcraft, A.J., Metzger, E.J., 2010. Concurrent simulation of the eddying general circulation and tides in an ocean model. Ocean Model 32, 175-187.

Arbic, B.K., Richman, J.G., Shriver, J.F., Timko, P.G., Metzger, E.J., Wallcraft, A.J., 2012. Global modelling of internal tides within an eddying ocean general circulation model. Oceanography 25, 20-29. https://doi.org/10.5670/oceanog.2012.38.

Arbic, B.K., Alford, M.H., Ansong, J.K., Buijsman, M.C., Ciotti, R.B., Farrar, J.T., Hallberg, R.W., Henze, C.E., Hill, C.N., Luecke, C.A., Menemenlis, D., Metzger, E.J., Müller, M.,
Nelson, A.D., Nelson, B.C., Ngodock, H.E., Ponte, R.M., Richman, J.G., Savage, A.C., Scott, R.B., Shriver, J.F., Simmons, H.L., Souopgui, I., Timko, P.G., Wallcraft, A.J., Zamudio, L., Zhang, Z., 2018, A primer on global internal tide and internal gravity wave continuum modeling in HYCOM and MITgcm, in "new Frontiers in operational oceanography", E. Chassignet, A. Pascual, J. Tintoré, and J. Verron, Eds., GODAE OceanView, 307-392, doi:10.17125/gov2018.ch13.

Barren, C.N., Smedstad, L.F., 2002. Global River inflow within the navy Coastal Ocean model, proceedings, MTS/IEEE oceans 2002. Conference 1472-1479.

Bauer, J.E., Cai, W.-J., Raymond, P.A., Bianchi, T.S., Hopkinson, C.S., Regnier, P.A.G., 2013. The changing carbon cycle of the coastal ocean. Nature 504, 61-70. https:// doi.org/10.1038/nature12857.

Belkin, I.M., Cornillon, P.C., Sherman, K., 2009. Fronts in large marine ecosystems. Prog. Oceanogr. 81, 223-236. https://doi.org/10.1016/j.pocean.2009.04.15.

Bowers, D.G., Simpson, J.H., 1987. Mean position of tidal fronts in European Shelf Sea. Cont. Shelf Res. 7, 35-44.

Buijsman, M.C., Arbic, B.K., Green, J.A.M., Helber, R.W., Richman, J.G., Shriver, J.F., Timko, P.G., Wallcraft, A., 2015. Optimizing internal wave drag in a forward barotropic model with semidiurnal tides. Ocean Model 85, 42-55. https://doi.org/10. 1016/j.ocemod.2014.11.003.

Buijsman, M.C., Ansong, J.K., Arbic, B.K., Richman, J.G., Shriver, J.F., Timko, P.G., Wallcraft, A.J., Whalen, C.B., Zhao, Z., 2016. Impact of parameterized internal wave drag on the semidiurnal energy balance in a Global Ocean circulation model. J. Phys. Oceanogr. 46, 1399-1419. https://doi.org/10.1175/JPO-D-15-0074.1.

Cancet, M., Lyard, F., Griffin, D., Carrere, L., Picot, N., 2017. Assessment of the FES2014 Tidal Currents on the Shelves Around Australia, $10^{\text {th }}$ Coastal Altimetry Workshop. Florence, Italy.

Carrere, L., Lyard, F., Cancet, M., Guillot, A., Picot, N., 2016. FES2014: A New Tidal Model - Validation Results and Perspectives for Improvements, Presentation to ESA Living Planet Conference. (Prague).

Chassignet, E.P., Hurlburt, H.E., Metzger, E.J., Smedstad, O.M., Cummings, J.A., Halliwell, G.R., Bleck, R., Baraille, R., Wallcraft, A.J., Lozano, C., Tolman, H.L., Srinivasan, A., Hankin, S., Cornillon, P., Weisberg, R., Barth, A., He, R., Werner, F., Wilkin, J., 2009. US GODAE: Global ocean prediction with the HYbrid Coordinate Ocean Model (HYCOM). Oceanography 22, 64-75. https://doi.org/10.5670/ oceanog.2009.39.

Chin, T.M., Vazquez-Cuervo, J., Armstrong, E.M., 2017. A multi-scale high-resolution analysis of global sea surface temperature. Remote Sens. Environ. 200, 154-169. https://doi.org/10.1016/j.res.2017.07.029.

Condie, S.A., Andrewartha, J.R., 2008. Circulation and connectivity on the Australian north west shelf. Cont. Shelf Res. 28, 1724-1739.

Cummins, P.F., Thupaki, P., 2018. A note on evaluating model tidal currents against observations. Cont. Shelf Res. 152, 35-37. https://doi.org/10.1016/j.csr.2017.10. 007.

Egbert, G.D., Erofeeva, S.Y., 2002. Efficient inverse modelling of barotropic ocean tides. J. Atmos. Ocean. Technol. 19, 183-204. https://doi.org/10.1175/1520-0426(2002) $019<0183$ :EIMOBO > 2.0.CO;2.

Egbert, G.D., Ray, R.D., 2001. Estimates of $\mathrm{M}_{2}$ tidal energy dissipation from TOPEX/ Poseidon altimeter data. J. Geophys. Res. 106 (C10), 22475-22502.

Egbert, G.D., Ray, R.D., 2003, Semi-diurnal and diurnal tidal dissipation from TOPEX/ Poseidon altimetry, Geophys. Res. Lett. 30, 1907, doi:https://doi.org/10.1029/ 2003GL017676, 17.

Egbert, G.D., Bennett, A.F., Foreman, M.G.G., 1994. TOPEX/POSEIDON tides estimated using a global inverse model. J. Geophys. Res. 99, 24821-24852. https://doi.org/10. 1029/94JC01894.

Flather, R.A., 1976. A tidal model of the northwest European continental shelf. Mem. Soc. R. Sci. Liege 10 (6), 141-164.

Flather, R.A., 1981, Results from a model of the north-east Atlantic relating to the Norwegian Coastal Current, Sætre, R. and M. Mork, Eds., Bergen University, Bergen, Norway, 427-458.

Foreman, M.G.G., 1977, Manual for tidal heights analysis and prediction, Pacific Marine Science Report 77-10, Institute of Ocean Sciences, Patricia Bay, Sidney, B.C., 58pp. (2004 revision).

Foreman, M.G.G., 1978, Manual for tidal current analysis and prediction, Pacific Marine Science Report 78-6, Institute of Ocean Sciences, Patricia Bay, Sidney, B.C., 57pp. (2004 revision).

Garrett, C.J.R., Keeley, J.R., Greenberg, D.A., 1978. Tidal mixing versus thermal stratification in the Bay of Fundy and Gulf of Maine. Atmos.-Ocean 16 (4), 403-423. https://doi.org/10.1080/07055900.1978.9649046.

Gerkema, T., Lam, F.-P.A., Maas, L.R.M., 2004. Internal tides in the Bay of Biscay: conversion rates and seasonal effects, Deep-Sea Res. II 51, 2995-3008. https://doi.org/ 10.1016/j.dsr2.2004.09.012.

Glorioso, P.D., 1987. Temperature distribution related to shelf-sea fronts on the Patagonian Shelf. Cont. Shelf Res. 7 (1), 27-34.

Glorioso, P.D., Flather, R.A., 1995. A barotropic model of the currents off SE South America. J. Geophys. Res. 100 (C7), 13,427-13,440.

Glorioso, P.D., Simpson, J.H., 1994. Numerical modelling of the M2 tide on the northern Patagonian Shelf, Cont. Shelf Res 14 (2/3), 267-278.

Griffiths, D.K., Pingree, R.D., Sinclair, M., 1981. Summer tidal fronts in the near-arctic regions of Foxe Basin and Hudson Bay. Deep-Sea Res. 28A (8), 865-873.

Guihou, K., Polton, J., Harle, J., Wakelin, S., O'Dea, E., Holt, J., 2018. Kilometric scale modeling of the North West European Shelf Seas: exploring the spatial and temporal variability of internal tides. J. Geophys. Res. Oceans 123, 688-707. https://doi.org/ 10.1002/2017JC012960.

Halliwell, G., KPP mixing algorithm, HYCOM Documentation, https://hycom.org/ attachments/067_kpp.pdf

Hannah, C.G., Dupont, F., Dunphy, M., 2009. Polynyas and tidal currents in the Canadian 
Arctic archipelago. Arctic 62 (1), 83-95.

Hendershott, M.C., 1972. The effects of solid earth deformation on global ocean tides. Geophys. J. R. Astron. Soc. 29, 389-402.

Hogan, T.F., Liu, M., Ridout, J.A., Peng, M.S., Whitcomb, T.R., Ruston, B.C., Reynolds, C.A., Eckermann, S.D., Moskaitis, J.R., Baker, N.L., McCormack, J.P., Viner, K.C., McLay, J.G., Flatau, M.K., Xu, L., Chen, C., Chang, S.W., 2014. The navy global environmental model. Oceanography 27 (3), 116-125. https://doi.org/10.5670/ oceanog.2014.73.

Holloway, P.E., 1983. Tides on the Australian North-west Shelf. Aust. J. Mar. Freshwat. Res. 34, 213-230.

Holloway, P.E., 2001. A regional model of the semidiurnal internal tide on the Australian north west shelf. J. Geophys. Res. 106 (C9), 19625-19638.

Holt, J., Umlauf, L., 2008. Modelling the tidal mixing fronts and seasonal stratification of the Northwest European Continental Shelf. Cont. Shelf Res. 28, 887-903.

Holt, J., Harle, J., Proctor, R., Michel, S., Ashworth, M., Batstone, C., Allen, I., Holmes, R., Smyth, T., Haines, K., Bretheron, D., Smith, G., 2009. Modelling the global coastal ocean. Phil. Trans. R. Soc. A 367, 939-951. https://doi.org/10.1098/rsta.2008.021.

Hunke, E.C., Lipscomb, W., 2008, CICE: the Los Alamos sea ice model, documentation and software user's manual, version 4.0, tech. Rep. LA-CC-06-012, Los Alamos National Laboratory, Los Alamos, NM.

ICES Dataset on Ocean Hydrography, 2014, The International Council for the Exploration of the Sea, Copenhagen, http://geo.ices.dk.

IMOS, 2017, Australian National Mooring Network (ANMN) facility - current velocity time-series, https://portal.aodn.org.au. Data was sourced from the Integrated Marine Observing System (IMO) - IMOS is a national collaborative research infrastructure, supported by the Australian government.

IMOS, 2018, Australian National Mooring Network (ANMN) facility - temperature and salinity time-series, https://portal.aodn.org.au, accessed: 14 June, 2018. Data was sourced from the Integrated Marine Observing System (IMO) - IMOS is a national collaborative research infrastructure, supported by the Australian government.

Jayne, S.R., St. Laurent, L.C., 2001, Parameterizing tidal dissipation over rough topography, Geophys. Res. Lett. 28, 811-814, doi:10.10129/2000GL012044.

Katavouta, A., Thompson, K.R., 2016. Downscaling ocean conditions with application to the Gulf of Maine. Scotian Shelf and adjacent deep ocean, Ocean Modelling 104, 54-72. https://doi.org/10.1016/j.ocemod.2016.05.007.

Kodaira, T., Thompson, K.R., Bernier, N.B., 2016. Prediction of M2 tidal surface currents by a global baroclinic ocean model and evaluation using observed drifter trajectories. J. Geophys. Res. Oceans 121, 6159-6183. https://doi.org/10.1002/2015JC011549.

Large, W.G., McWilliams, J.C., Doney, S.C., 1994. Oceanic vertical mixing: a review and a model with a nonlocal boundary layer parameterization. Rev. Geophys. 32, 363-403.

Liu, C., Allan, R.P., Berrisford, P., Mayer, M., Hyder, P., Loeb, N., Smith, D., Vidale, P.-L., Edwards, J.M., 2015. Combining satellite observations and reanalysis energy transports to estimate global net surface energy fluxes 1985-2012, J. Geophys. Res. Atmos. 120, 9374-9389. https://doi.org/10.1002/2015JD023264.

Loder, J.W., Greenberg, D.A., 1986. Predicted positions of tidal fronts in the Gulf of Maine region. Cont. Shelf Res. 6 (3), 397-414.

Lu, Y., Thompson, K.R., Wright, D.G., 2001. Tidal currents and mixing in the Gulf of St. Lawrence: an application of the incremental approach to data assimilation, Canadian Journal of Fisheries and Aquatic Sciences 58 (4), 723-735. https://doi.org/10.1139/ cjfas-58-4-723.

Luz Clara, M., Simionato, C.G., D'Onofrio, E., Moreira, D., 2015. Future sea level rise and changes on tides in the Patagonian continental shelf, J. Coastal Res. 31 (3), 519-535. https://doi.org/10.2112/JCOASTRES-D-13-00127.1.

Lyard, F., Carrere, L., Cancet, M., Guillot, A., Picot, N., 2017 (in prep), FES2014: A new finite elements tidal model for global ocean. (in prep. for submission to Ocean Dynamics).

Madec, G., 2008, NEMO ocean engine, Note du Pole de modélisation, Institut PierreSimon Laplace (IPSL), France, No 27, ISSN No 1288-1619.

Martin, M.J., Hines, A., Bell, M.J., 2007. Data assimilation in the FOAM operational shortrange ocean forecasting system: a description of the scheme and its impact, Q. J. Met. Soc. 133 (625), 981-995.

Mellor, G.L., 2004. Users Guide for a Three-Dimensional, Primitive Equation, Numerical Ocean Model. Princeton Univ, Princeton, N.J.

Moreira, D., Simionato, C.G., Dragani, W.C., Nuñez, M.N., 2009. Tidal and residual currents observations at the san Matías and San José gulfs, northern Patagonia, Argentina. J. Coast. Res. 25 (4), 957-968. https://doi.org/10.2112/08-1035.1.

Moreira, D., Simionato, C.G., Dragani, W., 2011. Modeling ocean tides and their energetics in the north Patagonia gulfs of Argentina. J. Coast. Res. 27 (1), 87-102. https://doi.org/10.2112/JCOASTRES-D-09-00055.1.

Nash, J.D., Shroyer, E.L., Kelly, S.M., Inall, M.E., Duda, T.F., Levine, M.D., Jones, N.L.,
Musgrave, R.C., 2012. Are any coastal internal tides predictable? Oceanography 25 (2), 80-95. https://doi.org/10.5670/oceanog.2012.44.

Ngodock, H.E., Souopgui, I., Wallcraft, A.J., Richman, J.G., Shriver, J.F., Arbic, B.K., 2016. On improving the accuracy of the M2 barotropic tides embedded in a highresolution global ocean circulation model. Ocean Model 97, 16-26. https://doi.org/ 10.1016/j.ocemod.2015.10.011.

O'Dea, E.J., Arnold, A.K., Edwards, K.P., Fumer, R., Hyder, P., Martine, M.J., Siddom, J.R., Storkey, D., While, J., Holt, J.T., Liu, H., 2012. An operational ocean forecast system incorporating NEMO and SST data assimilation for the tidally driven European North-West Shelf. J. Oper. Oceanogr. 5 (1), 3-17.

Pawlowicz, R., Beardsley, B., Lentz, S., 2002. Classical tidal harmonic analysis including error estimates in MATLAB using T-TIDE. Comput. Geosci. 28, 929-937.

Pingree, R.D., Griffiths, D.K., 1978. Tidal fronts on the shelf seas around the British Isles. J. Geophys. Res. 83 (C9), 4615-4622.

Pingree, R.D., Griffiths, D.K., 1980. A numerical model of the $\mathrm{M}_{2}$ tide in the Gulf of St. Lawrence. Oceanol. Acta 3 (2), 221-225.

Ray, R.D., 1998. Ocean self-attraction and loading in numerical tidal models, Mar. Geodesy 21, 181-192.

Reynolds, R.W., Rayner, N.A., Smith, T.M., Stokes, D.C., Wang, W., 2002. An improved in situ and satellite SST analysis for climate. J. Clim. 15, 1609-1625.

Savage, A.C., Arbic, B.K., Richman, J.G., Shriver, J.F., Alford, M.H., Buijsman, M.C., Farrar, J.T., Sharma, H., Voet, G., Wallcraft, A.J., Zamudio, L., 2017. Frequency content of sea surface height variability from internal gravity waves to mesoscale eddies. J. Geophys. Res. Oceans 122, 2519-2538. https://doi.org/10.1002/ 2016JC012331.

Schlichting, H., 1968. Boundary Layer Theory. McGraw-Hill 748pp.

Scott, R.B., Furnival, D.G., 2013. A guide to GMACMD. 53pp.

Shriver, J.F., Arbic, B.K., Richman, J.G., Ray, R.D., Metzger, E.J., Wallcraft, A.J., Timko, P.G., 2012. An evaluation of the barotropic and internal tides in a high-resolution global circulation tide model. J. Geophys. Res. 117, C10024. https://doi.org/10. 1029/2012JC008170.

Shriver, J.F., Richman, J.G., Arbic, B.K., 2014. How stationary are the internal tides in a high-resolution global ocean circulation model? J. Geophys. Res. Oceans 119 , 2769-2787. https://doi.org/10.1002/2013JC009423.

Simpson, J.H., 1981. The shelf-sea fronts: implications of their existence and behaviour. Philos. Trans. R. Soc. Lond. A 302, 531-546.

Simpson, J.H., Bowers, D., 1981. Models of stratification and frontal movement in shelf seas. Deep-Sea Res. 28A (7), 727-738.

Simpson, J.H., Hunter, J.R., 1974. Fronts in the Irish Sea. Nature 250, 404-406.

Simpson, J.H., Allen, C.M., Morris, N.C.G., 1978. Fronts on the continental shelf. J. Geophys. Res. 83 (C9), 4607-4614.

Stammer, D., Ray, R.D., Andersen, O.B., Arbic, B.K., Bosch, W., Carrère, L., Cheng, Y., Chinn, D.S., Dushaw, B.D., Egbert, G.D., Erofeeva, S.Y., Fok, H.S., Green, J.A.M., Griffiths, S., King, M.A., Lapin, V., Lemoine, F.G., Luthcke, S.B., Lyard, F., Morison, J., Müller, M., Padman, L., Richman, J.G., Shriver, J.F., Shum, C.K., Taguchi, E., Yi, Y., 2014. Accuracy assessment of global barotropic ocean tide models. Rev. Geophys. 52, 243-282. https://doi.org/10.1002/2014RG000450.

Storkey, D., Blockley, E.W., Furner, R., Guivarch'h, C., Lea, D., Martin, M.J., Barciela, R.M., Hines, A., Hyder, P., Siddorn, J.R., 2010. Forecasting the ocean state using NEMO: the new FOAM system, J. Operational Oceanography 3 (1), 3-15. https://doi. org/10.1080/1755876X.2010.11020109.

Takeoka, H., Kandea, A., Anami, H., 1997. Tidal fronts induced by horizontal contrast of vertical mixing efficiency. J. Oceanogr. 53, 563-570.

Timko, P.G., Arbic, B.K., Richman, J.G., Scott, R.B., Metzger, E.J., Wallcraft, A.J., 2012. Skill tests of three-dimensional tidal currents in a global ocean model: a look at the North Atlantic. J. Geophys. Res. 117, C08014. https://doi.org/10.1029/ 2011JC007617.

Timko, P.G., Arbic, B.K., Richman, J.G., Scott, R.B., Metzger, E.J., Wallcraft, A.J., 2013. Skill testing a three-dimensional global tide model to historical current meter records. J. Geophys. Res. Oceans 118, 6914-6933. https://doi.org/10.1002/2013JC009071.

Tong, J., Gan, Z., Qi, Y., Mao, Q., 2010. Predicted positions of tidal fronts in continental shelf of South China Sea. J. Mar. Syst. 82, 145-153.

Tranter, D.J., Leech, G.S., 1987. Factors influencing the standing crop of phytoplankton on the Australian Northwest Shelf seaward of the $40 \mathrm{~m}$ isobaths, Cont. Shelf Res. 7 (2), 115-133.

Zhabin, I.A. and Dubina, V.A., 2012, The Structure of the Tidal Mixing Front in the Region of Shantar Islands (Sea of Okhotsk) According to Data of Satellite Observations, Izvestiya, Atmos. And Oceanic Physics 48, 9, 999-1005, doi:https://doi.org/10. 1134/S0001433812090174. (Original Russian text published in Issledovanie Zemli iz Kosmosa 2012, 2, 83-99). 